\title{
A Prospective, Multicenter, Phase I Matched-Comparison Group Trial of Safety, Pharmacokinetics, and Preliminary Efficacy of Riluzole in Patients with Traumatic Spinal Cord Injury
}

\author{
Robert G. Grossman, ${ }^{1, *}$ Michael G. Fehlings, ${ }^{2,{ }^{*}}$ Ralph F. Frankowski, ${ }^{3}$ Keith D. Burau, ${ }^{3}$ Diana S.L. Chow, \\ Charles Tator, ${ }^{2}$ Angela Teng, ${ }^{4}$ Elizabeth G. Toups, James S. Harrop, ${ }^{5}$ Bizhan Aarabi, ${ }^{6}$ Christopher I. Shaffrey, \\ Michele M. Johnson, ${ }^{8}$ Susan J. Harkema, ${ }^{9}$ Maxwell Boakye, ${ }^{9}$ James D. Guest, ${ }^{10}$ and Jefferson R. Wilson ${ }^{2}$
}

\begin{abstract}
A prospective, multicenter phase I trial was undertaken by the North American Clinical Trials Network (NACTN) to investigate the pharmacokinetics and safety of, as well as obtain pilot data on, the effects of riluzole on neurological outcome in acute spinal cord injury (SCI). Thirty-six patients, with ASIA impairment grades A-C (28 cervical and 8 thoracic) were enrolled at 6 NACTN sites between April 2010 and June 2011. Patients received $50 \mathrm{mg}$ of riluzole PO/NG twice-daily, within $12 \mathrm{~h}$ of SCI, for 14 days. Peak and trough plasma concentrations were quantified on days 3 and 14 . Peak plasma concentration $\left(\mathrm{C}_{\max }\right)$ and systemic exposure to riluzole varied significantly between patients. On the same dose basis, $\mathrm{C}_{\max }$ did not reach levels comparable to those in patients with amyotrophic lateral sclerosis. Riluzole plasma levels were significantly higher on day 3 than on day 14, resulting from a lower clearance and a smaller volume of distribution on day 3. Rates of medical complications, adverse events, and progression of neurological status were evaluated by comparison with matched patients in the NACTN SCI Registry. Medical complications in riluzole-treated patients occurred with incidences similar to those in patients in the comparison group. Mild-to-moderate increase in liver enzyme and bilirubin levels were found in $14-70 \%$ of patients for different enzymes. Three patients had borderline severe elevations of enzymes. No patient had elevated bilirubin on day 14 of administration of riluzole. There were no serious adverse events related to riluzole and no deaths. The mean motor score of 24 cervical injury riluzole-treated patients gained 31.2 points from admission to 90 days, compared to 15.7 points for 26 registry patients, a 15.5 -point difference $(p=0.021)$. Patients with cervical injuries treated with riluzole had more-robust conversions of impairment grades to higher grades than the comparison group.
\end{abstract}

Key words: clinical trial; neuroprotection; riluzole; spinal cord injury

\section{Introduction}

$\mathbf{T}$ There IS CURRENTLY no neuroprotective therapy that has emerged as a standard of care after traumatic spinal cord injury (SCI). After a traumatic injury, the spinal cord undergoes a prolonged series of biological processes of reaction and repair.
Therapies have been directed toward limiting the damage to the spinal cord and enhancing repair at each stage of the process. The general categories of therapy have been neuroprotection to limit the secondary injury that occurs after acute trauma, modulating the inflammatory response to injury, modifying the glial and fibroblastic scar that blocks regrowth of axons, and stimulating regrowth

\footnotetext{
${ }^{1}$ Houston Methodist Research Institute, Department of Neurosurgery, Houston Methodist Hospital, Houston, Texas.

${ }^{2}$ Department of Surgery, Division of Neurosurgery and Spine Program, University of Toronto. Toronto, Ontario, Canada.

${ }^{3}$ Division of Biostatistics, University of Texas School of Public Health, Houston, Texas.

${ }^{4}$ Department of Pharmacological and Pharmaceutical Sciences, University of Houston, Houston, Texas.

${ }^{5}$ Department of Neurosurgery, Thomas Jefferson University, Philadelphia, Pennsylvania.

${ }^{6}$ Department of Neurosurgery, University of Maryland, Baltimore, Maryland.

${ }^{7}$ Department of Neurosurgery, University of Virginia, Charlottesville, Virginia.

${ }^{8}$ Department of Neurosurgery, University of Texas Health Science Center, Houston, Texas.

${ }^{9}$ Department of Neurosurgery, University of Louisville, Louisville, Kentucky.

${ }^{10}$ Department of Neurosurgery, University of Miami, Miami, Florida.

*Drs. Grossman and Fehlings share first author status.
} 
and repair of damaged axons and providing substrates to guide axons and bridge gaps. Substantial repair of SCI will probably require the application of a series of therapies, each directed toward a particular phase of the reactive and reparative processes.

Early within the secondary injury cascade, the initial trauma force, in combination with subsequent ischemic changes, leads to neuronal membrane dysfunction, which includes the constitutive activation of voltage-gated sodium ion channels. ${ }^{1-3}$ This pathologic continuous activation causes a marked increase in intracellular sodium levels and leads to an influx of calcium ions through the sodium-calcium exchange pump. ${ }^{4,5}$ Rises in intracellular calcium concentration then lead to the extracellular release of toxic levels of the excitatory neurotransmitter glutamate. ${ }^{6}$ The combination of these events leads to increased regional cellular death as a result of ionic imbalance, formation of reactive oxidative ions, intracellular energy failure, cytotoxic edema formation, and glutamatergic excitotoxicity.

Riluzole, a sodium-channel blocking medication, which is U.S. Food and Drug Administration (FDA) approved for the treatment of amyotrophic lateral sclerosis (ALS), ${ }^{7}$ has been shown to improve the outcome of SCI in preclinical studies. ${ }^{8,9}$ Twelve preclinical studies of riluzole efficacy in acute rodent models of SCI, published between 1996 and 2011, have recently been summarized in a review article on neuroprotective drug therapy and SCI. ${ }^{10}$ In comparison to control animals, riluzole-treated animals exhibited reduced tissue cavitation and better preservation of white matter, motor neurons, mitochondrial function, somatosensory-evoked potentials, and locomotor scores in different studies. ${ }^{10}$ Recent work evaluating the timing of riluzole administration in rats revealed that treatment initiated at both 1 and $3 \mathrm{~h}$ postinjury resulted in improved neurobehavioral outcomes as well as tissue-preserving effects. ${ }^{11}$ The presence of a well-defined target mechanism and demonstration of beneficial effects in pre-clinical studies, combined with its tolerability in the ALS population, make riluzole an attractive candidate for evaluation to treat acute human SCI. ${ }^{12}$ With this background, a phase I prospective, matched-comparison group trial of the pharmacokinetics (PK), safety, and preliminary efficacy of riluzole as a neuroprotective agent in acute traumatic SCI was carried out with the following goals to:

1. Test the feasibility of a trial of a therapy that must be administered within $12 \mathrm{~h}$ of acute traumatic SCI.

2. Study the PK and pharmacodynamics of riluzole in SCI.

3. Obtain data on the safety of riluzole in SCI using a matched cohort group for comparison.

4. Obtain exploratory pilot data on the effects of riluzole on measures of neurological outcome after SCI using a matched cohort group for comparison.

5. Relate the pharmacology of riluzole in SCI to safety and outcome measures.

\section{Methods}

\section{Organization of the trial by the North American Clinical Trials Network}

The trial was registered with ClinicalTrials.gov (identifier: NCT00876889). Planned enrollment of 36 patients was conducted between April 12, 2010 and June 20, 2011 at six clinical centers of the North American Clinical Trials Network (NACTN) for Treatment of Spinal Cord Injury (Table 1). NACTN is a consortium of clinical centers composed of neurosurgery department faculty and staff caring for SCI patients at university-affiliated hospitals, a coordinating center, a data management center and a pharmaco-
Table 1. Trial Sites

\begin{tabular}{ll}
\hline Trial sites & Principal investigators \\
\hline $\begin{array}{l}\text { Thomas Jefferson University, } \\
\text { Philadelphia }\end{array}$ & James S. Harrop, MD \\
$\begin{array}{l}\text { University of Maryland, } \\
\text { Baltimore }\end{array}$ & Bizhan Aarabi, MD \\
University of Virginia, & Christopher I. Shaffrey, MD \\
Charlottesville & \\
University of Texas Health & Michele M. Johnson, MD \\
Science Center, Houston & \\
University of Louisville, & Susan J. Harkema, PhD \\
Louisville & Maxwell Boakye, MD \\
University of Toronto, & Michael G. Fehlings, MD, PhD \\
Toronto & Charles H. Tator, MD, PhD \\
\hline
\end{tabular}

logical center. Each NACTN clinical center has one or two principal investigators and a study coordinator who is a physician or a clinical research nurse. NACTN was established in 2005 with the support of the Christopher Reeve Foundation, which is its sponsoring organization. ${ }^{13,14}$ The Telemedicine and Advanced Technology Research Center (TATRC), United States Army Medical Research and Materiel Command (USAMRMC), has supported NACTN since 2006. Partial grant support for this trial was also received from AOSpine, which helped to facilitate the trial design and initial logistics of trial implementation.

\section{Trial design: Riluzole treatment cohort and eligibility criteria}

The trial was a multi-site, single-arm, open-label-treatment pilot study with an enrollment goal of 36 patients. Eligibility criteria are given in Table 2. A detailed description of the trial design has been

Table 2. Eligibility Criteria

Inclusion criteria

Age $\geq 18$ and $\leq 70$ years

Written informed consent by patient or legally authorized representative to participate in the study

No other life-threatening injury

Nonpenetrating spinal cord injury at neurologic level from $\mathrm{C} 4$ to T11

ASIA Impairment Scale grade A, B, or C

No cognitive impairment that would preclude an informed consent, including moderate or severe traumatic brain injury Initial dose of riluzole within $12 \mathrm{~h}$ of injury

Exclusion criteria

Hypersensitivity to riluzole or any of its components

Unable to receive riluzole orally or by nasogastric tube

History of liver or kidney disease (e.g., hepatitis A, B, or C or cirrhosis)

A recent history of regular substance abuse (illicit drugs or alcohol)

Unconscious

Penetrating spinal cord injury

Pregnancy as established by urine pregnancy test

Currently involved in another spinal cord injury research study

Has a mental disorder or other illness, which, in the view of the site investigator, would preclude accurate medical and neurological evaluation

Unable to commit to the follow-up schedule

Is a prisoner

Unable to converse, read, and write in English at the elementaryschool level 
published previously. ${ }^{15}$ The sample size of this safety study was established in advance and was based on complication rates observed in NACTN registry data ${ }^{13}$ and discussed below. The incidence rates of complications were expected to range from 0.15 to 0.30 in patients not treated with riluzole. Using a one-sided exact binomial test with a type I error rate of $5 \%$, a case series of 36 patients receiving riluzole was projected to have approximate power of $0.80-0.99$ to detect doubling of the complication rate in the riluzole case series.

\section{Comparison group: North American Clinical Trials Network Spinal Cord Injury Registry group}

As a phase I trial, the study did not have a concurrent control group of patients who did not receive riluzole, but who otherwise received the same standard of care treatment as the riluzole cohort. In lieu of a concurrent control group with which to compare the safety and neurological outcome data for the riluzole cohort, a comparison group was formed of 36 SCI patients who had received standard-of-care treatment at the NACTN clinical centers, whose records were in the NACTN SCI Registry. The NACTN SCI Registry contains information about the clinical courses of 594 SCI patients admitted to the NACTN clinical centers from October 2005 through November 2012, who consented to having data on their injury recorded in an institutional review board (IRB)- and human research protection office (HRPO)-approved data registry. Information was collected prospectively under the following headings: demographic data; medical history; initial clinical status; Glasgow Coma Score (GCS); Abbreviated Injury Score; International Standards For Neurological Classification of Spinal Cord Injury (ISNCSCI) motor, sensory, and impairment scores; type of neurological injury; type of bony injury; imaging of cord and canal diameters on computed tomography, magnetic resonance imaging, or myelogram; traction-reduction; medical therapy; surgical therapy; complications, including cardiac, pulmonary, hematological, gastrointestinal (GI), genitourinary (GU); infectious; skin; and neuropsychiatric. ${ }^{14}$

Data from 36 registry patients meeting the eligibility criteria for the riluzole patients were matched with the 36 patients treated with riluzole. Criteria for registry cases included admission to a NACTN center within $12 \mathrm{~h}$ of injury, American Spinal Injury Association (ASIA) Impairment Scale (AIS) grade A, B, or C at admission, cervical or thoracic injury, nonpenetrating SCI at neurological level from $\mathrm{C} 4$ to $\mathrm{C} 11$, and GCS $>13$. Registry cervical and thoracic cases were then matched by AIS grade to the riluzole patients' neurological level of injury, gender, and age. This hierarchy of matching was the method adopted to select among multiple matches. All matching was blinded to outcome measures in the registry and riluzole groups. Thirty ( $83 \%$ ) of the 36 registry patients were drawn from five of the six NACTN sites trialing riluzole in the present study.

\section{Determination of riluzole dose and dosing schedule}

Riluzole (50 mg; Rilutek ${ }^{\circledR}$; Sanofi-Aventis, Bridgewater, NJ) was administered every $12 \mathrm{~h}$ orally or by nasogastric tube, starting within $12 \mathrm{~h}$ of injury for 28 doses.

The riluzole dose was determined by using human data and by scaling from animal data. ${ }^{16}$ From the human data, the most conservative approach was used, based on the FDA-approved dose for ALS patients. In dose-ranging studies of riluzole in ALS that used doses of 50,100, and $200 \mathrm{mg} /$ day, a daily dose of $50 \mathrm{mg}$ twice-daily (b.i.d.) of riluzole was confirmed to have the best benefit-to-risk ratio. $^{17}$

From animal data, the human equivalent dose (HED) was allometrically scaled from the animal dose $(6 \mathrm{mg} / \mathrm{kg}$ b.i.d.) in female Wistar rats (weight, 250-300 g) and was calculated with the equation from FDA Guidance for Industry $(2005)^{18}$ :

$$
\begin{aligned}
\text { HED } & =\text { Animal Dose }(\mathrm{mg} / \mathrm{kg}) \times(\text { animal wt } / \text { human wt in } \mathrm{kg})^{0.33} \\
& =(6 \mathrm{mg} / \mathrm{kg} \mathrm{bid}) \times(0.25 \mathrm{~kg} / 70 \mathrm{~kg})^{0.33} \\
& =0.92 \mathrm{mg} / \mathrm{kg} \text { bid }=64.2 \mathrm{mg} / 70 \mathrm{~kg} \text { b.i.d. }
\end{aligned}
$$

The trial dose of $50 \mathrm{mg}$ b.i.d. was set conservatively below the HED of $64.2 \mathrm{mg}$ b.i.d., scaled from the effective, safe animal dose of $6 \mathrm{mg} / \mathrm{kg}$ b.i.d. ${ }^{11}$ and in concordance with the dose of $50 \mathrm{mg}$ b.i.d. that achieved the best safety and efficacy balance in ALS patients. ${ }^{17}$

The time window of $12 \mathrm{~h}$ after injury for administration of riluzole is in concordance with a study of delayed postinjury administration of riluzole in a preclinical model of moderate cervical SCI. ${ }^{11}$ Riluzole treatment at $1 \mathrm{~h}$ and at $3 \mathrm{~h}$ postinjury both provided locomotor improvement. Differences in metabolic rate and time course of appearance of inflammatory biomarkers in rodents and humans suggest that pathological changes in SCI peak 4-6 times more rapidly in rat than in human SCI, making $12 \mathrm{~h}$ a reasonable exploratory time window for a phase I trial of riluzole. ${ }^{11}$ The mean time and standard deviation (SD) of SCI patients receiving the first dose of riluzole in the present study was $8.7 \pm 2.2 \mathrm{~h}$.

\section{Pharmacology of riluzole in spinal cord injury patients}

The PK of riluzole in the 36 patients in the present study have been published in detail. ${ }^{16}$ Plasma samples for PK study were collected $1-2 \mathrm{~h}$ predose and $2 \mathrm{~h}$ postdose for trough and peak concentrations, respectively, on days 3 and 14 after the initial dose. Findings that are pertinent to the phase I clinical trial are given below in the Results section of this report.

\section{Patient care protocol}

Patients received care for SCI as described in the Guidelines for the Management of Acute Cervical Spine and Spinal Cord Injuries. ${ }^{19}$ Treatment included rapid ventilatory, cardiovascular and nutritional support, reduction of vertebral subluxations, surgical decompression of the spinal cord and vertebral stabilization, and prophylactic measures to prevent deep vein thrombosis (DVT) using leg compression devices and/or anticoagulation with heparin or low molecular weight heparin. Administration of corticosteroids, generally methylprednisolone (MPSS), was in accord with the policies of the admitting center. Thirty-nine percent of the riluzole and $58 \%$ of the registry patients received MPSS.

\section{Schedule of events and data collection}

Table 3 shows the schedule of events for the study, the riluzole dosing schedule, and the clinical and laboratory data that were collected on admission to the study, during acute hospitalization, and at $42 \pm 7,90 \pm 10$, and $180 \pm 14$ days.

\section{Screening and admission to the study}

SCI patients examined in the emergency department (ED) within $12 \mathrm{~h}$ of injury were screened for eligibility and had the study explained to them and to legally authorized representatives, if present. Consenting individuals were then enrolled in the trial. Time of enrollment was taken as the time of admission to the study, and the measurements referred to in the tables as admission data were made at this time, before receiving riluzole. For the purpose of recording and tracking riluzole administration, the day on which the first dose of riluzole was given was designated as day 1 of the study.

\section{Data collection}

Data were collected prospectively, daily when required by the protocol, by NACTN clinical coordinators working together with the principal investigators of each clinical site. Data were recorded 


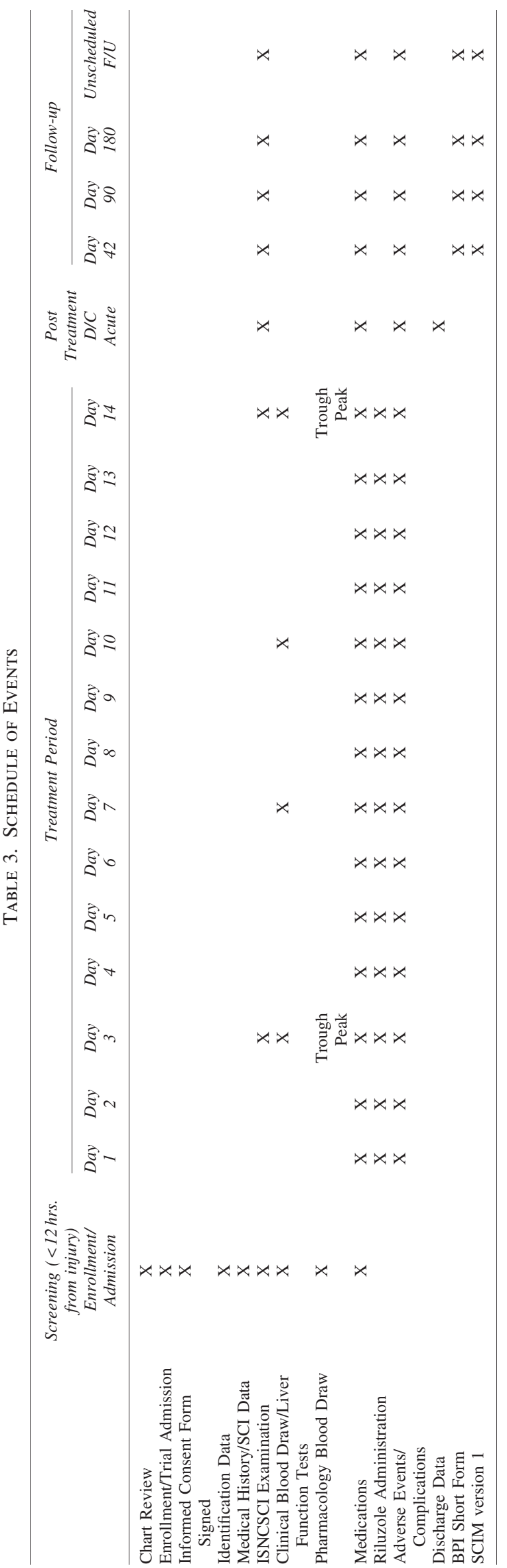

on 16 case-report forms, throughout the course of the acute care hospitalization of the patients and at the follow-up visits made in the rehabilitation hospital or at the clinical center. The following data were collected:

1. Prehospitalization demographic data, past medical history, preinjury medication use, circumstances and time of injury, and time of arrival to the ED of the admitting NACTN hospital.

2. Evaluation of the medical condition of the patient.

3. Measurement of neurological status with ISNCSCI motor and sensory and AIS examinations. ${ }^{20}$ Evaluations were repeated on days 3 and 14 of acute hospitalization, before and after spinal surgery, and at the 42-, 90-, and 180-day examinations. The Spinal Cord Independence Measure $(\mathrm{SCIM})^{21}$ was performed at 90 and 180 days.

4. Details of the medical and surgical therapy received.

5. Hematology and blood chemistries, including liver function tests, were drawn on admission to the study and on days 3,7 , 10 , and 14 and when medically indicated at 42, 90, and 180 days.

6. Medical complications and serious adverse events (SAEs) were assessed by NACTN principal investigators by observation of the patients with input of the clinical coordinators as well as medical and nursing staff. Categorization and severity level of complications were determined by the principal investigators using the criteria described in an analysis of the incidence and severity of acute complications after SCI, based on data from the NACTN SCI Registry. ${ }^{22}$

All data were submitted to the data management center and were subjected to multiple manual and electronic data quality-control procedures.

\section{Compliance with regulatory requirements}

1. Approval of the protocol by the HRPO of the Department of Defense (DoD).

2. Harmonization of the IRB requirements of each center with requirements of the HRPO; final approval of the harmonized protocol and the informed consent form by each IRB.

3. Appointment of a central trial medical monitor, a physiatrist at a university unaffiliated with any of the centers, who received reports of all SAEs.

4. Appointment of a local medical monitor at each clinical center who received reports of adverse events at that center.

\section{Training of personnel and trial initiation meeting}

Two training meetings were held at the Frazier Rehab Institute for the principal investigators and study coordinators, reviewing in detail the study protocol, the Guidelines for the Management of Acute Cervical Spine and Spinal Cord Injuries ${ }^{19}$ and in performing ASIA examinations on individuals with SCI under the guidance of skilled instructors.

A trial initiation meeting of all investigators and coordinators was held at The Methodist Hospital Coordinating Center, including a 2-day review of the protocol, the schedule of events, the rules and procedures for reporting adverse events, and stopping rules.

\section{Site monitoring}

NACTN's study monitor conducted on-site visits to the clinical centers and reviewed case report forms, source documentation, and on-site regulatory binders to ensure regulatory and protocol compliance with Good Clinical Practices. 


\section{Statistical analysis}

Admission characteristics of riluzole and registry patients were compared using two-sample independent $t$-tests and two-sample chi-square methods or Fisher's exact test, as appropriate, for categorical data. Chi-square methods were also used to compare the incidence of medical complications between the two groups. Total motor scores for riluzole and registry patients stratified by impairment grade at admission were analyzed using the permutation test for independent samples, with motor scores as the raw observations. The permutation test makes no assumptions about the shapes of the underlying distributions or dispersions of motor scores and is particularly effective for skewed data. Permutation tests were computed using StatXact 8 with Cytel Studio software (Cytel Inc., Cambridge, MA).
Box plots were used to compare distributions of 90- and 180-day gains in total motor score and pin-prick sensory scores for the riluzole and registry groups. Box plots show the middle $50 \%$ of the data by a box that extends from the 25 th to the 75 th percentile and tails (whiskers) that contain at least $99 \%$ of the data and markers that indicate any outlying data values. Sample medians are shown within each box. Box plots are labeled for ease in interpretation and comparison. All graphics and other statistical tests were computed using StatCorp (2009) Stata statistical software (Release 11; StataCorp LP, College Station, TX).

\section{Results}

The enrollment goal of the study was fulfilled. Thirty-six patients with acute traumatic injury to the spinal cord (ages, 18-69),

\section{N Enrolled Level $\quad$ Admission N with Complete Motor Scores at Day after Injury}

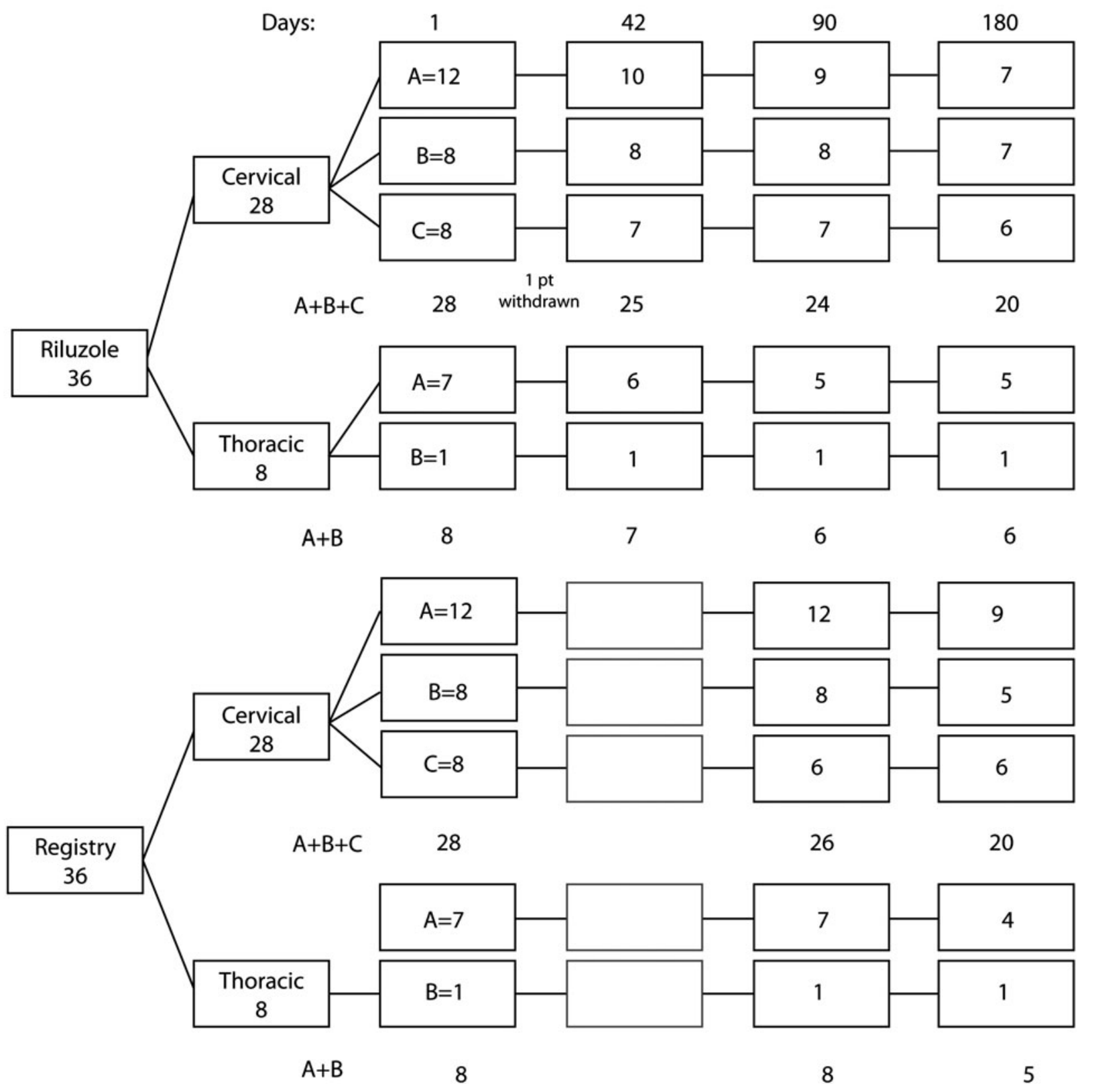

FIG. 1. Patient flow diagram of numbers of riluzole and registry patients available with complete motor scores on admission and at 42 , 90, and 180 days. 
impairment grades A-C, with levels of injury (lowest normal motor level) C4-T11, were enrolled at six NACTN clinical center hospitals between April 12, 2010 and June 20, 2011 and received riluzole enterally within $12 \mathrm{~h}$ of injury at a dose of $50 \mathrm{mg}$ every $12 \mathrm{~h}$ for a total of 28 doses.

\section{Cervical and thoracic injuries-riluzole and registry} cohorts: Impairment grade on admission, demographics, cause of injury, hours to admission to emergency department and surgery, and corticosteroid administration

Figure 1 provides an overview of patient flow for safety and neurological outcome data, stratified by cervical and thoracic sites of injury and impairment grade. There were no statistically significant differences in demographics or clinical variables for the riluzole and registry patient groups (Table 4 ). Table 4 shows that
$28(78 \%)$ injuries in the riluzole cohort were cervical and $8(22 \%)$ were thoracic.

Patients in the registry cohort were selected to match the numbers of cervical and thoracic injuries, neurological levels of injury, and impairment scale grades of the patients in the riluzole cohort. Distribution of impairment grades for both the riluzole and the registry cohorts was $19 \mathrm{~A}, 9 \mathrm{~B}$, and $8 \mathrm{C}$. Thirty $(83 \%)$ patients were male and $6(17 \%)$ were female in the riluzole cohort. The gender ratio was nearly identical in the registry cohort. The mean age was 41.3 years for patients with cervical injuries and 45.4 for patients with thoracic injuries, with a range of 18-69 in the riluzole cohort. The mean age for the cervical injuries in the registry cohort was 40.8 years. The causes of injury were predominantly motor vehicle accidents $(N=20)$ and falls $(N=9)$ in the riluzole cohort; the causes in the registry cohort were similar. Mean hours from injury to ED were $3.0 \pm 1.8$ for riluzole patients with cervical injuries and $2.5 \pm 2.3$ for registry patients.

Table 4. Cervical and Thoracic Injuries: Demographics and Clinical Variables on Admission To Study in Riluzole and Registry Patients

\begin{tabular}{|c|c|c|c|c|c|}
\hline Variable & $\begin{array}{c}\text { Riluzole } \\
\text { Cervical } \mathrm{N}=28\end{array}$ & $\begin{array}{c}\text { Registry } \\
\text { Cervical } \mathrm{N}=28\end{array}$ & $\mathrm{p}$ value & $\begin{array}{c}\text { Riluzole } \\
\text { Thoracic } \mathrm{N}=8\end{array}$ & $\begin{array}{c}\text { Registry } \\
\text { Thoracic } \mathrm{N}=8\end{array}$ \\
\hline \multicolumn{6}{|l|}{ AIS } \\
\hline A & 12 & 12 & & 7 & 7 \\
\hline $\mathrm{B}$ & 8 & 8 & & 1 & 1 \\
\hline $\mathrm{C}$ & 8 & 8 & & 0 & 0 \\
\hline Total & 28 & 28 & Matched & 8 & 8 \\
\hline Age in years & $41.3 \pm 17.4$ & $40.8 \pm 14.4$ & 0.91 & $45.4 \pm 16.4$ & $30.4 \pm 17.7$ \\
\hline \multicolumn{6}{|l|}{ Gender } \\
\hline Male & 24 & 23 & & 6 & 8 \\
\hline Female & 4 & 5 & & 2 & 0 \\
\hline Total & 28 & 28 & 1.00 & 8 & 8 \\
\hline \multicolumn{6}{|l|}{ Cause } \\
\hline Motor vehicle accident & 13 & 8 & & 7 & 6 \\
\hline Fall & 8 & 11 & & 1 & 2 \\
\hline Sports & 5 & 8 & & 0 & 0 \\
\hline Assault & 2 & 1 & & 0 & 0 \\
\hline Total & 28 & 28 & 0.52 & 8 & 8 \\
\hline Hours to hospital ED & $3.0 \pm 1.8$ & $2.4 \pm 2.3$ & 0.28 & $3.6 \pm 1.7$ & $2.7 \pm 2.9$ \\
\hline \multicolumn{6}{|l|}{ Surgery } \\
\hline Yes & 25 & 28 & & 8 & 8 \\
\hline No & 3 & 0 & & 0 & 0 \\
\hline Total & 28 & 28 & 0.24 & 8 & 8 \\
\hline \multicolumn{6}{|l|}{ Hours to surgery } \\
\hline 6-12 & 14 & 11 & & 1 & 2 \\
\hline $12-24$ & 7 & 9 & & 3 & 2 \\
\hline $24-48$ & 3 & 3 & & 4 & 3 \\
\hline$>48$ & 1 & 5 & & 0 & 1 \\
\hline Total & 25 & 28 & 0.42 & 8 & 8 \\
\hline Body mass index & $26.4 \pm 4.1$ & $27.0 \pm 4.2$ & 0.59 & $28.1 \pm 4.3$ & $26.1 \pm 1.9$ \\
\hline \multicolumn{6}{|l|}{ Surgical approach } \\
\hline Anterior & 4 & 7 & & 0 & 1 \\
\hline Posterior & 7 & 10 & & 5 & 7 \\
\hline Both & 14 & 11 & & 3 & 0 \\
\hline Total & 25 & 28 & 0.52 & 8 & 8 \\
\hline \multicolumn{6}{|l|}{ Corticosteroids } \\
\hline Yes & 10 & 17 & & 4 & 4 \\
\hline No & 18 & 11 & & 4 & 4 \\
\hline Total & 28 & 28 & 0.11 & 8 & 8 \\
\hline
\end{tabular}

AIS, American Spinal Injury Association Impairment Scale; ED, emergency department. 
Thirty-three $(92 \%)$ of the riluzole patients underwent early surgery for spinal cord decompression and vertebral column stabilization, $42 \%$ within $6-12 \mathrm{~h}$ of injury, and another $28 \%$ in 12-24h. Three of the cervical injuries did not undergo surgery. Median hours from injury to surgical decompression and stabilization were $11.3 \mathrm{~h}$ for cervical injuries and 23.6 for thoracic injuries for the riluzole cohort and were similar for the registry cohort. Surgical approaches were anterior $(4 ; 12 \%)$, posterior $(12$; $36 \%)$, and both $(17 ; 51 \%)$ for the riluzole cohort and were similar for the registry group.

Corticosteroids were administered at the time of admission to $39 \%$ of the riluzole cohort and $58 \%$ of the registry group.

The mean duration of initial hospitalization of the riluzole cohort was 17 days (range, 5-41). Thirty-five patients were discharged to a rehabilitation hospital and 1 to a nursing facility. The mean duration of hospitalization for the registry cohort was 23 days.

The leading pre-existing medical conditions in the riluzole cohort were hypertension (10 patients) and diabetes mellitus (5 patients) and were similar in the registry cohort.

Neurological levels of injury for cervical and thoracic patients receiving riluzole and for registry patients are shown in Table 5.

Table 5. Cervical and Thoracic Injuries: Riluzole and Registry Patients: Neurological Levels of InJury

\begin{tabular}{|c|c|c|}
\hline Level of injury & $\mathrm{N}(\%)$ & $\%$ of cervical \\
\hline \multicolumn{3}{|l|}{ Riluzole cervical $\mathrm{N}=28$} \\
\hline $\mathrm{C} 4$ & $13(36.1)$ & 46.4 \\
\hline $\mathrm{C} 5$ & $7(19.4)$ & 25.0 \\
\hline C6 & $7(19.4)$ & 25.0 \\
\hline $\mathrm{C} 8$ & $1(2.8)$ & 3.6 \\
\hline Total cervical & $28(77.8)$ & $(100)$ \\
\hline Level of injury & $\mathrm{N}(\%)$ & $\%$ of thoracic \\
\hline \multicolumn{3}{|l|}{ Riluzole thoracic $\mathrm{N}=8$} \\
\hline $\mathrm{T} 1$ & $2(5.6)$ & 25.0 \\
\hline $\mathrm{T} 2$ & $2(5.6)$ & 25.0 \\
\hline T6 & $1(2.8)$ & 12.5 \\
\hline T9 & $1(2.8)$ & 12.5 \\
\hline $\mathrm{T} 11$ & $2(5.5)$ & 25.0 \\
\hline Total thoracic & $8(22.2)$ & $(100)$ \\
\hline Total cervical and thoracic & $36(100)$ & \\
\hline Level of injury & $\mathrm{N}(\%)$ & $\%$ of cervical \\
\hline \multicolumn{3}{|l|}{ Registry cervical $\mathrm{N}=28$} \\
\hline $\mathrm{C} 4$ & $11(30.6)$ & 39.3 \\
\hline $\mathrm{C} 5$ & $10(27.8)$ & 35.7 \\
\hline C6 & $6(16.7)$ & 21.4 \\
\hline $\mathrm{C} 8$ & $1(2.8)$ & 3.6 \\
\hline Total cervical & $28(77.8)$ & $(100)$ \\
\hline Level of injury & $\mathrm{N}(\%)$ & $\%$ of thoracic \\
\hline \multicolumn{3}{|l|}{ Registry thoracic $\mathrm{N}=8$} \\
\hline $\mathrm{T} 1$ & $3(8.3)$ & 37.5 \\
\hline T6 & $2(5.5)$ & 25.0 \\
\hline $\mathrm{T} 10$ & $1(2.8)$ & 12.5 \\
\hline $\mathrm{T} 11$ & $1(2.8)$ & 12.5 \\
\hline $\mathrm{T} 12$ & $1(5.5)$ & 12.5 \\
\hline Total thoracic & $8(22.2)$ & $(100)$ \\
\hline Total cervical and thoracic & $36(100)$ & \\
\hline
\end{tabular}

For the patients with cervical injuries in the riluzole cohort, C4-level injuries predominated $(N=13 ; 46 \%$ of cervical injuries), followed by $\mathrm{C} 5$ and $\mathrm{C} 6(N=7 ; 25 \%$ each $)$ and $\mathrm{C} 8(N=1$; $4 \%)$. Among the thoracic injuries, $4(50 \%)$ were high thoracic, at $\mathrm{T} 1$ and $\mathrm{T} 2$, respectively, $2(25 \%)$ were mid-thoracic, at T6 and T9, and 2 were low thoracic, at T11. Seven of the eight thoracic injuries were impairment grade $\mathrm{A}$ on admission and one was B. Levels of injury were similar for riluzole and registry patients.

Distribution of impairment grades on admission for each level of injury for patients receiving riluzole is shown in Table 6. Distribution was similar for registry patients.

\section{Time to riluzole administration and number of doses received}

The mean time to the first dose of riluzole was $8.7 \mathrm{~h}$ for the riluzole cohort $(n=36)$ as a whole (Table 7$)$. Thirty-five patients completed the study. The goal of administering 28 doses of riluzole was reached in $71 \%$ of these 35 patients; an additional $26 \%$ received 27 doses and $3 \%$ received 26 doses.

\section{Patient withdrawal}

One patient was withdrawn on the seventh day of receiving riluzole when his liver function tests showed a moderate elevation of gamma-glutamyl transpeptidase (GGT). This patient was a 69-year-old man with previous comorbidities of emphysema and hypertension. He had sustained a C4 injury in a fall (impairment grade $\mathrm{C}$ ). He developed respiratory failure on day 2 and pneumonia on day 4. GGT was normal on admission and on day 4, but had risen to $4.6 \times$ the upper limit of normal (ULN) on day 7 . He was receiving medications that can impair liver function. Riluzole was stopped as a precautionary measure to prevent possible liver damage. GGT fell to a mildly elevated level on day 10 . Impairment grade was $C$ at 90 days postinjury and GGT was normal.

\section{Pharmacokinetics of riluzole in spinal cord injury patients}

A detailed report of the PK of riluzole in the patients in this study has been published. ${ }^{16}$ The following will summarize the key data that are of pertinence to the current report. Riluzole PK were evaluated in 33 patients on day 3 and in 32 patients on day 14, as

Table 6. Cervical Injuries: Riluzole and Registry Patients: Neurological Level and Distribution OF IMPAIRMENT GRADES ON ADMISSION

\begin{tabular}{lcccr}
\hline Level & $A$ & $B$ & $C$ & Total \\
\hline Riluzole: & impairment grade & & & \\
C4 & 5 & 4 & 4 & 13 \\
C5 & 2 & 3 & 2 & 7 \\
C6 & 4 & 1 & 2 & 7 \\
C8 & 1 & 0 & 0 & 1 \\
Total & 12 & 8 & 8 & 28 \\
Registry: impairment grade & & & \\
C4 & 5 & 4 & 2 & 11 \\
C5 & 2 & 3 & 5 & 10 \\
C6 & 4 & 1 & 1 & 6 \\
C8 & 1 & 0 & 0 & 1 \\
Total & 12 & 8 & 8 & 28 \\
\end{tabular}


Table 7. Cervical and Thoracic Injuries: Time to Riluzole Administration

\begin{tabular}{lccccc}
\hline Time window & Minimum $(h)$ & 25th percentile $(h)$ & Median/mean $(h)(S D)$ & $75^{\text {th }}$ percentile $(h)$ & Maximum $(h)$ \\
\hline $\begin{array}{l}\text { Injury to admission } \\
\quad N=36\end{array}$ & 0.7 & 1.5 & $2.3 / 3.0(1.8)$ & 4.2 & 7.0 \\
$\begin{array}{l}\text { Injury to riluzole } \\
N=36\end{array}$ & 3.7 & 6.9 & $8.5 / 8.7(2.2)$ & 10.6 & 12.1 \\
\hline
\end{tabular}

SD, standard deviation.

both $\mathrm{C}_{\text {peak }}$ and $\mathrm{C}_{\text {trough }}$ samples of patients were collected and quantifiable. The plasma concentration and the systemic exposure to riluzole (area under the plasma-concentration curve; $\mathrm{AUC}_{0-12}$ ) varied significantly among patients. Maximum concentration $\left(\mathrm{C}_{\max }\right)$ ranged from 24 to $409 \mathrm{ng} / \mathrm{mL}$ (mean, $129 \pm 14$; standard error [SE]) on days 3 and 9 to $317 \mathrm{ng} / \mathrm{mL}$ (mean, $77 \pm 14$; SE) on day 14.

The PK of riluzole $-\mathrm{C}_{\max }, \mathrm{C}_{\min }, \mathrm{AUC}_{0-12}$, clearance (CL), and volume of distribution $(\mathrm{V})$ - changed during the acute and subacute phases of SCI during the 14 days of administration, a phenomenon consistently observed in all patients at all clinical sites. Mean $\mathrm{C}_{\max }$, $\mathrm{C}_{\text {min }}$, and $\mathrm{AUC}_{0-12}(129 \mathrm{ng} / \mathrm{mL}, 46 \mathrm{ng} / \mathrm{mL}$, and $982 \mathrm{ng} * \mathrm{~h} / \mathrm{mL}$, respectively) were significantly higher on day 3 than on day 14 ( $77 \mathrm{ng} / \mathrm{mL}, 19 \mathrm{ng} / \mathrm{mL}$, and $521 \mathrm{ng} * \mathrm{~h} / \mathrm{mL}$, respectively), resulting from lower CL ( 50 vs. $106 \mathrm{~L} / \mathrm{h})$ and a smaller V (557 vs. $1298 \mathrm{~L})$ on day $3 .^{16}$

\section{Safety: Medical complications and serious adverse events}

SCI patients have a high incidence of physiological disturbances and medical complications occurring acutely after injury as documented in a recent publication of data from the NACTN SCI Registry. ${ }^{22}$ Using the definitions of severe and moderate complications described in that article, the incidence of complications occurring within 30 days of injury was determined. Table 8 shows medical complications and SAEs tabulated both by frequency of occurrence of specific types of complications (e.g., infection and pulmonary) and by the number of individuals sustaining one or more complication. Complications reported as SAEs are marked with a superscript $b$.

Table 9 shows the number of patients in the riluzole and registry groups who sustained at least 1 complication involving one or more of the seven organs or systems by which complications were classified and the incidences of these complications. There was no significant difference between the two groups.

The frequency of specific types of severe and moderate complications, expressed as a percentage of the total number of complications, was also compared to that reported in 315 patients in the NACTN SCI Registry. ${ }^{22}$ For riluzole versus registry, the comparisons were the following: infection, including pneumonia (26 vs. $22 \%$ ); pulmonary, including pulmonary embolism, respiratory failure, lobar collapse, atelectasis, and pneumothorax (23 vs. 27\%); hematological, including DVT, anemia, thrombocytopenia, and coagulopathy (12 vs. 15\%); cardiac, including asystole, bradycardia, arrhythmia, and shock (7 vs. 13\%); neurological/psychiatric, including neuropathic pain and depression and anxiety (15 vs. 7\%); GI/GU, including bleeding and bowel obstruction (11 vs. 9\%); and skin, including pressure sores (8 vs. $7 \%$ ).

There were no SAEs attributable to riluzole. There were no deaths.

\section{Table 8. Cervical and Thoracic Injuries: Riluzole Patients ${ }^{\mathrm{a}}$}

Complications $\quad \begin{gathered}\text { No. of } \\ \text { complications }\end{gathered}$

Infection: 19 complications (14 patients)

Urinary tract infection $\quad 10$

Pneumonia 5

Staphylococcal infection of skin 2

Sepsis ${ }^{b}$

Infectious diarrhea

Pulmonary: 17 complications (11 patients)

Respiratory failure

Lobar collapse/atelectasis

Pneumothorax

Acute respiratory distress syndrome ${ }^{\mathrm{b}} \quad 2$

Pleural effusion 1

Bronchial obstruction mucus plug, syncope ${ }^{\mathrm{b}} \quad 1$

Pulmonary embolus ${ }^{b}$

Neurological/psychiatric: 11 complications (10 patients)

Neuropathic pain 4

Depression 3

Anxiety 2

Agitation $\quad 1$

Elevation of sensory level ${ }^{\mathrm{b}}$

Hematological: 9 complications (7 patients)

Deep venous thrombosis ${ }^{\mathrm{b}}$

Thrombocytopenia 2

Neutropenia 1

Coagulopathy 1

Thrombophlebitis 1

Severe anemia

Gastrointestinal: 7 complications (5 patients)

Prolonged nausea/vomiting 3

Rectal hemorrhage ${ }^{\mathrm{b}} \quad 1$

Dysphagia 1

Anal fistula 1

Bowel obstruction $^{\mathrm{b}} \quad 1$

Skin: 6 complications (4 patients)

Pressure-damaged skin areas other than sacral 3

Sacral decubiti 2

Rash: allergic reaction 1

Cardiovascular: 5 complications (5 patients)

Prolonged arrhythmia $\quad 2$

Asystolic episode ${ }^{\mathrm{b}} \quad 1$

Prolonged bradycardia $(<50 \mathrm{bpm}) \quad 1$

Prolonged shock $(\mathrm{BP}<80 \mathrm{mmHg}) \quad 1$

${ }^{a}$ Seventy-four severe and moderate medical complications and 12 serious adverse events within 30 days of admission in 36 patients.

${ }^{\mathrm{b}}$ Reported as a serious adverse event (total, $N=12$ ).

bpm, beats per minute; BP, blood pressure. 
Table 9. Cervical and Thoracic Injuries: Riluzole and Registry Patients: Incidence of Medical Complications AND $P$ VALUES OF DifFERENCES

\begin{tabular}{|c|c|c|c|c|c|}
\hline \multirow[b]{2}{*}{ System/category } & \multicolumn{2}{|c|}{ Riluzole $\mathrm{N}=36$} & \multicolumn{2}{|c|}{ Registry $\mathrm{N}=36$} & \multirow[b]{2}{*}{$\mathrm{p}$ value* } \\
\hline & Patients $^{\mathrm{a}}$ & Incidence $e^{\mathrm{b}}$ & Patients $^{\mathrm{a}}$ & Incidence $e^{\mathrm{b}}$ & \\
\hline Infection & 14 & 0.389 & 13 & 0.361 & 0.81 \\
\hline Pulmonary & 11 & 0.306 & 16 & 0.444 & 0.22 \\
\hline Neuropsychiatric & 10 & 0.278 & 8 & 0.222 & 0.59 \\
\hline Hematological & 7 & 0.194 & 9 & 0.250 & 0.57 \\
\hline Cardiovascular & 5 & 0.139 & 11 & 0.306 & 0.09 \\
\hline GI/GU & 5 & 0.139 & 9 & 0.250 & 0.19 \\
\hline Skin & 4 & 0.111 & 3 & 0.083 & 0.69 \\
\hline
\end{tabular}

${ }^{a}$ Number of patients with at least one complication of the specified system.

${ }^{\mathrm{b}}$ Incidence of complications within 30 days of injury.

*Pearson's chi-square test for comparing two proportions.

GI, gastrointestinal; GU, genitourinary.

\section{Safety: Elevation of liver enzymes and bilirubin above the upper limit of normal}

Liver enzymes and bilirubin were monitored on admission and during administration of riluzole. On admission, elevated levels of different liver enzymes and bilirubin were found in $9-37 \%$ of patients. Thirteen percent of patients had mild ( $>$ ULN to $2.5 \times$ ULN) or moderate $(>2.5-5 \times \mathrm{ULN})$ elevations of alanine transferase (ALT), 37\% had mild or moderate elevations of aspartate transaminase (AST), $11 \%$ had mild elevations of GGT, and $9 \%$ had mild elevations of bilirubin (Table 10; Fig. 2). Some patients had elevation of a single enzyme, whereas others had two or three enzymes elevated.

During administration of riluzole, liver enzymes and bilirubin were monitored on days $3,7,10$, and 14 . Incidence of elevation of enzyme levels increased during administration of riluzole, with increasing frequency in the second week of administration. Seventy percent of patients had mild or moderate elevations of ALT and

Table 10. Cervical and Thoracic Injuries:

Liver EnZyme and Bilirubin Elevations

at Admission and DURing Riluzole Administration ${ }^{a}$

\begin{tabular}{lccccc}
\hline \multicolumn{7}{c}{$A L T$} & AST & ALP & GGT & Bilirubin \\
& $\mathrm{N}(\%)$ & $\mathrm{N}(\%)$ & $\mathrm{N}(\%)$ & $\mathrm{N}(\%)$ & $\mathrm{N}(\%)$ \\
\hline Admission & before riluzole & & & \\
Normal & $27(87)$ & $20(62)$ & $32(100)$ & $25(89)$ & $29(91)$ \\
Mild $^{\mathrm{b}}$ & $3(10)$ & $8(25)$ & $0(0)$ & $3(11)$ & $3(9)$ \\
Moderate $^{\mathrm{c}}$ & $1(3)$ & $4(12)$ & $0(0)$ & $0(0)$ & $0(0)$ \\
Severe $^{\mathrm{d}}$ & $0(0)$ & $0(0)$ & $0(0)$ & $0(0)$ & $0(0)$ \\
Total $^{2}$ & $31(100)$ & $32(100)$ & $32(100)$ & $28(100)$ & $32(100)$ \\
While receiving riluzole & & & \\
Normal $_{\text {Mild }}^{\mathrm{b}}$ & $10(28)$ & $12(33)$ & $30(83)$ & $15(44)$ & $31(86)$ \\
Moderate $^{\mathrm{c}}$ & $15(42)$ & $16(44)$ & $5(14)$ & $13(38)$ & $4(11)$ \\
Severe $^{\mathrm{d}}$ & $10(28)$ & $7(19)$ & $1(3)$ & $5(15)$ & $1(3)$ \\
Total $^{2}$ & $36(100)$ & $36(100)$ & $36(100)$ & $34(100)$ & $36(100)$ \\
\hline
\end{tabular}

${ }^{\mathrm{a}}$ See Figure 2.

${ }^{\mathrm{b}}$ Mild: $>\mathrm{ULN}$ to $2.5 \times \mathrm{ULN}$.

${ }^{\mathrm{c}}$ Moderate: $>2.5-5 \times \mathrm{ULN}$.

${ }^{\mathrm{d}}$ Severe: $>5-20 \times$ ULN

ALT, alanine aminotransferase; AST, aspartate aminotransferase; ALP, alkaline phosphatase; GGT, gamma-glutamyl transpeptidase; ULN, upper limit of normal.
$63 \%$ of AST on at least one of the days of testing. One patient had a borderline severe elevation of ALT $(6 \times \mathrm{ULN}$; (severe defined as $>5-20 \times \mathrm{ULN})$. Another patient had a borderline severe elevation of AST $(5.5 \times \mathrm{ULN})$. These elevations returned to normal at 3 and 6 months. Fifty-three percent of patients had mild or moderate elevations of GGT, and 1 patient had a borderline severe elevation of GGT $(7 \times \mathrm{ULN})$. Seventeen percent had mild or moderate elevations of alkaline phosphatase (ALP). Fourteen percent had mild or moderate elevation of bilirubin (Table 10; Fig. 2).

No patient had elevated bilirubin on day 14, the last day of administration of riluzole. The appearance of an increased level of a liver enzyme was not necessarily followed by a progressive increase in the level of that enzyme. In many cases, the elevated concentration had returned to a normal level at the next date of testing. The elevation of one enzyme was not necessarily linked to the elevation of another enzyme.

No relationship was found between the $\mathrm{C}_{\max }$ of riluzole and liver enzyme levels.

\section{Neurological outcome}

Neurological outcome was assessed with ISNCSCI total motor score progression, sensory score progression, impairment grade conversion, and SCIM. Each measure was assessed separately for cervical and thoracic injury cohorts and stratified by impairment grades $\mathrm{A}, \mathrm{B}$, and $\mathrm{C}$.

\section{Cervical injuries: Progression of motor scores from admission to 42, 90, and 180 days}

A flow diagram of the subgroups of the riluzole and registry cohorts, stratified as described above and the number of patients with complete ISNCSCI motor data available for comparison on the specified days after injury, is shown in Figure 1.

After withdrawal of 1 patient (C4 level of injury impairment grade C, see above, "Patient withdrawal"), there were 27 with cervical injuries available for measurement of motor scores. The impairment grades and numbers of these patients were A-12, B-8, and C-7. Motor score outcomes in the riluzole-treated cohort were compared with those in a matched cohort of patients drawn from the NACTN SCI Registry (Table 4). The progression of the total motor scores from admission to 42 days for the riluzole cohort, and to 90 and 180 days for the riluzole and registry cohorts, is shown in Table 11 and illustrated graphically in Figure 3. Table 11 shows the 
ALT

RZ

Baseline

8

AST

Baseline

ALP

$\mathrm{RZ}$

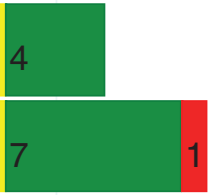

Baseline

GGT

$\mathrm{RZ}$

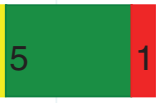

Baseline

3

Bilirubin

$\mathrm{RZ}$

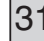

4

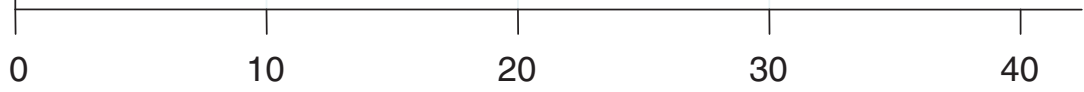

Frequency

Normal

Mild

Moderate

Severe

FIG. 2. Cervical and thoracic injuries: frequency of normal and elevated liver enzymes and bilirubin. See Table 10. ALT, alanine transferase; AST, aspartate transamine; ALP, alkaline phosphatase; GGT, gamma-glutamyl transpeptidase; RZ, riluzole. 
Table 11. Cervical Injuries: Riluzole and Registry Patients

\begin{tabular}{|c|c|c|c|c|c|c|}
\hline \multirow[b]{2}{*}{ Admission } & \multirow[b]{2}{*}{$\mathrm{N}$} & \multicolumn{2}{|c|}{ Riluzole } & & \multirow{2}{*}{\multicolumn{2}{|c|}{ Registry }} \\
\hline & & Admission $^{\mathrm{a}}$ mean $(S D)$ & 42-day mean (SD) & & & \\
\hline $\mathrm{A}$ & 10 & $16.8(15.9)$ & $24.0(16.1)$ & & & \\
\hline B & 8 & $16.4(10.1)$ & $44.5(25.6)$ & & & \\
\hline $\mathrm{C}$ & 7 & $30.3(23.0)$ & $64.4(28.1)$ & & & \\
\hline All & 25 & $20.4(17.2)$ & $41.9(27.8)$ & & & \\
\hline Admission to 90 days & $\mathrm{N}$ & Admission $^{\mathrm{b}}$ mean $(S D)$ & 90-day mean (SD) & $\mathrm{N}$ & Admission $^{\mathrm{d}}$ mean $(S D)$ & 90-day mean (SD) \\
\hline A & 9 & $14.6(9.3)$ & $27.3(26.3)$ & 12 & $21.6(14.2)$ & $31.9(19.9)$ \\
\hline B & 8 & $16.4(10.1)$ & $55.4(28.1)$ & 8 & $19.9(9.2)$ & $31.0(22.9)$ \\
\hline $\mathrm{C}$ & 7 & $30.3(23.0)$ & $76.1(18.8)$ & 6 & $36.7(13.0)$ & $68.8(18.1)$ \\
\hline All & 24 & $19.7(15.7)$ & $50.9(31.5)$ & 26 & $24.5(13.9)$ & $40.2(25.4)$ \\
\hline Admission to 180 days & $\mathrm{N}$ & Admission ${ }^{\mathrm{c}}$ mean $(S D)$ & 180-day mean ( $S D)$ & $\mathrm{N}$ & Admission ${ }^{\mathrm{e}}$ mean $(S D)$ & 180-day mean (SD) \\
\hline A & 7 & $16.1(8.7)$ & $31.4(29.6)$ & 9 & $23.3(13.8)$ & $34.8(20.8)$ \\
\hline $\mathrm{B}$ & 7 & $14.6(9.4)$ & $60.3(24.6)$ & 5 & $22.4(11.1)$ & $46.6(32.5)$ \\
\hline $\mathrm{C}$ & 6 & $32.0(24.5)$ & $81.8(23.9)$ & 6 & $33.0(13.9)$ & $84.0(12.3)$ \\
\hline All & 20 & $20.4(16.6)$ & $56.6(32.5)$ & 20 & $26.0(13.4)$ & $52.5(30.3)$ \\
\hline
\end{tabular}

Sample size, mean, and standard deviation of motor scores at 42,90 , and 180 days are stratified by admission impairment grade (see Fig. 3). See consort diagram, Figure 1, and graph, Figure 3.

${ }^{\text {a Includes }} 25$ riluzole patients with both an admission and 42-day motor score.

${ }^{b}$ Includes 24 riluzole patients with both an admission and 90-day motor score.

${ }^{c}$ Includes 20 riluzole patients with both an admission and 180-day motor score.

${ }^{\mathrm{d}}$ Includes 26 registry patients with both an admission and 90-day motor score.

${ }^{\mathrm{e}}$ Includes 20 registry patients with both an admission and 180-day motor score.

$\mathrm{SD}$, standard deviation.
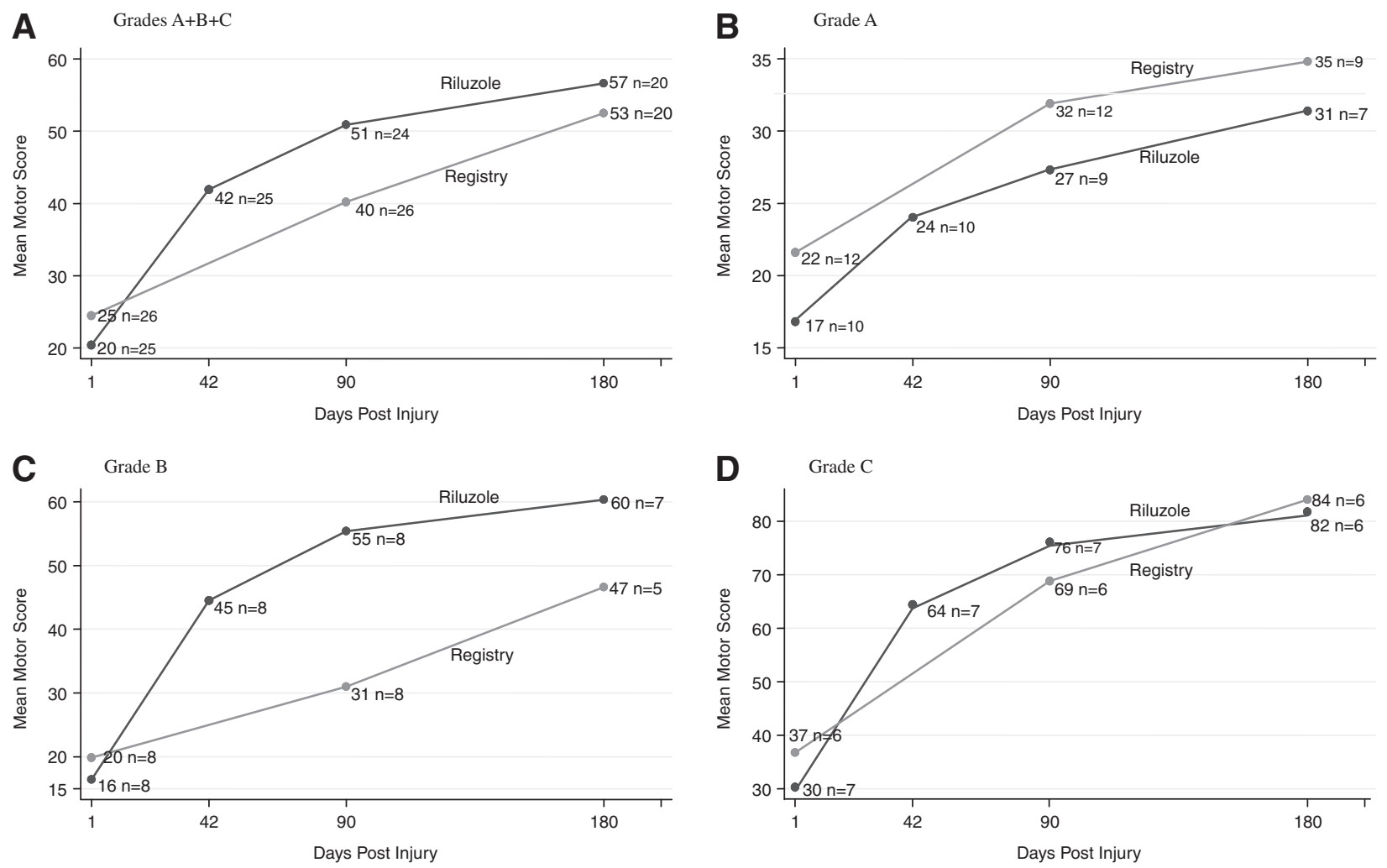

FIG. 3. Cervical injuries: riluzole and registry patients. Progression of mean total motor score (and $n$ patients available) at admission and 42, 90, and 180 days, stratified by admission impairment grade. (A) All grades. (B) Grade A. (C) Grade B. (D) Grade C. See Table 11 . 
Table 12. Cervical Injuries: Riluzole and Registry Patients: Motor Score Mean Changes From Admission to 90 Days AND From Admission to 180 Days

\begin{tabular}{|c|c|c|c|c|c|c|c|}
\hline Admission AIS & $\mathrm{N}$ & $\begin{array}{l}\text { Riluzole } \\
\text { 90-day change mean (SD) }\end{array}$ & $\mathrm{N}$ & $\mathrm{N}$ & $\begin{array}{c}\text { Registry } \\
\text { 90-day change mean (SD) }\end{array}$ & $\begin{array}{l}\text { Riluzole: registry } \\
\text { difference mean }\end{array}$ & $\mathrm{p}$ value* \\
\hline A & 9 & $12.7(20.7)$ & 12 & 12 & $10.3(17.1)$ & 2.4 & 0.787 \\
\hline B & 8 & $39.0(28.7)$ & 8 & 8 & $11.1(17.4)$ & 27.9 & 0.037 \\
\hline $\mathrm{C}$ & 7 & $45.8(16.0)$ & 7 & 6 & $32.1(19.3)$ & 13.7 & 0.194 \\
\hline $\mathrm{All}^{\mathrm{a}}$ & 24 & $31.2(26.2)$ & 27 & 26 & $15.7(19.3)$ & 15.5 & 0.021 \\
\hline Admission AIS & $\mathrm{N}$ & 180-day change mean (SD) & $\mathrm{N}$ & $\mathrm{N}$ & 180-day change mean (SD) & $\begin{array}{l}\text { Riluzole: registry } \\
\text { difference mean }\end{array}$ & $\mathrm{p}$ value* \\
\hline A & 7 & $15.3(9.3)$ & 7 & 9 & $11.4(17.2)$ & 3.9 & 0.715 \\
\hline B & 7 & $45.7(10.8)$ & 5 & 5 & $24.2(24.8)$ & 21.5 & 0.208 \\
\hline $\mathrm{C}$ & 6 & $49.8(8.4)$ & 5 & 6 & $51.0(9.7)$ & -1.2 & 0.911 \\
\hline $\mathrm{All}^{\mathrm{b}}$ & 20 & $36.3(28.5)$ & 18 & 20 & $26.5(24.0)$ & 9.8 & 0.248 \\
\hline
\end{tabular}

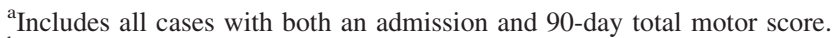

${ }^{\mathrm{b}}$ Includes all cases with both an admission and 180-day total motor score.

*Exact $p$ values based on the nonparametric permutation test for two independent samples.

AIS, American Spinal Injury Association (ASIA) Impairment Scale; SD, standard deviation.

absolute motor scores at admission and at 90 and 180 days, stratified by impairment grade on admission and for the cohort as a whole. Table 12 shows the change in scores from admission to 90 and to 180 days, stratified by impairment grade on admission and for the cohort as a whole.

Table 11 (upper panel) presents the progression of the mean total motor score for 25 riluzole patients with cervical injuries from admission to 42 days postinjury. The table includes only patients with admission and 42-day scores. Patients are stratified by impairment grades $\mathrm{A}, \mathrm{B}$, and $\mathrm{C}$ and by $\mathrm{A}+\mathrm{B}+\mathrm{C}$, that is, the entire group taken as a whole (all).

Ten patients (admission impairment grade A) progressed from an admission mean motor score of 16.8 to 24.0 at 42 days, gaining 7.2 points and achieving $76 \%$ of the score of 31.4 reached at 180 days by 7 of these patients, as shown in the lowest panel of the table.

Eight patients (admission impairment grade B and motor score of 16.4) progressed to a score of 44.5 at 42 days, a gain of 28.1 points and achieved $74 \%$ of the score of 60.3 reached at 180 days by 7 of these patients.

Seven patients (admission impairment grade $\mathrm{C}$ and motor score of 30.3) progressed to a score of 64.4 , a gain of 34.1 points, and achieved $79 \%$ of the score of 81.8 reached at 180 days by 6 of these patients.

For all grades, the group of 25 riluzole patients had a mean admission motor score of 20.4, progressed to a score of 41.9 at 42 days, a gain of 21.5 points, and achieved $74 \%$ of the score of 56.6 reached at 180 days by 20 of these patients, as shown in the lowest panel of the table.

The progression of motor scores to 90 and to 180 days for riluzole patients and registry patients, stratified by impairment grades, is shown in the middle and lowest panels, respectively, of Table 11 and is displayed graphically in Figure 3.

Table 11 (middle panel) compares the motor scores for 24 riluzole and 26 registry patients at 90 days postinjury, stratified by impairment grade. The table includes only patients with motor scores for those dates. Data for both the riluzole and registry groups, each taken as a whole (all), are shown in the lowest row of the panel and are displayed graphically in Figure 3A. For the 90day comparison, the scores on admission were 19.7 for the riluzole cohort and 24.5 for the registry cohort. At 90 days, the riluzole cohort had progressed to a score of 50.9 and the registry cohort to a score of 40.2.

The lowest panel shows the scores at 180 days. At 180 days, the motor score for all patients was 56.6 for 20 riluzole patients and 52.5 for 20 registry patients.

The greatest gains in mean motor score occurred in grade B patients. The score of riluzole B patients went from 16.4 on admission to 55.4 at 90 days. At 180 days, the score of 7 riluzole B patients went from 14.6 to 60.3 (a 4.13-fold gain). The gain in bilateral lower extremity motor score (LEMS) exceeded that of the bilateral upper extremity motor score (UEMS). The gain in LEMS for 8 patients from admission to 90 days was 25.9 points and for UEMS, 13.1 points. The gain in LEMS for 7 patients from admission to 180 days was 29 points and for UEMS, 14.9 points.

The next-greatest gains were for C-grade patients, with a 2.45 fold gain at 90 days and 2.56-fold gain at 180 days. Grade A patients had the lowest gains (1.86-fold at 90 days and 1.95-fold at 180 days).

Table 12 presents the change of motor score and the riluzole cohort-registry cohort difference in the gain of scores and $p$ values. The data are stratified by impairment grades and for the cohort as a whole for patients with admission and 90-day scores and patients with admission and 180-day scores.

For grade A patients, the riluzole-registry mean difference at 90 days was 2.4 points $(p=0.787)$; for grade $\mathrm{B}$ patients, 27.9 ( $p=0.037)$; for grade $\mathrm{C}$ patients, $13.7(p=0.194)$. For the entire cohort, the difference was 15.5 (significant at $p=0.021$ ). The score for the grade B patients contributed the largest effect toward the significance value for the entire group.

At 180 days, the riluzole-registry difference for grade B patients was $21.5(p=0.208)$ and for grade $\mathrm{C}$ patients, $-1.2(p=0.911)$. For all patients, the difference was $9.8(p=0.248)$.

Figure 4 presents a box-plot comparison of the gains in motor scores from admission to 90 days for 24 riluzole patients and for 26 registry patients, as well as for 20 patients of each group at 180 days. Box plots show the median gain and the 75th and 25 th percentiles and the maximum and minimum values for both groups. The median is used rather than the mean because the data are skewed toward higher motor score values, and thus a mean does not adequately locate the center of the data. This is particularly true for the 90-day gains. At 90 days, the median value was 23.5 for the 

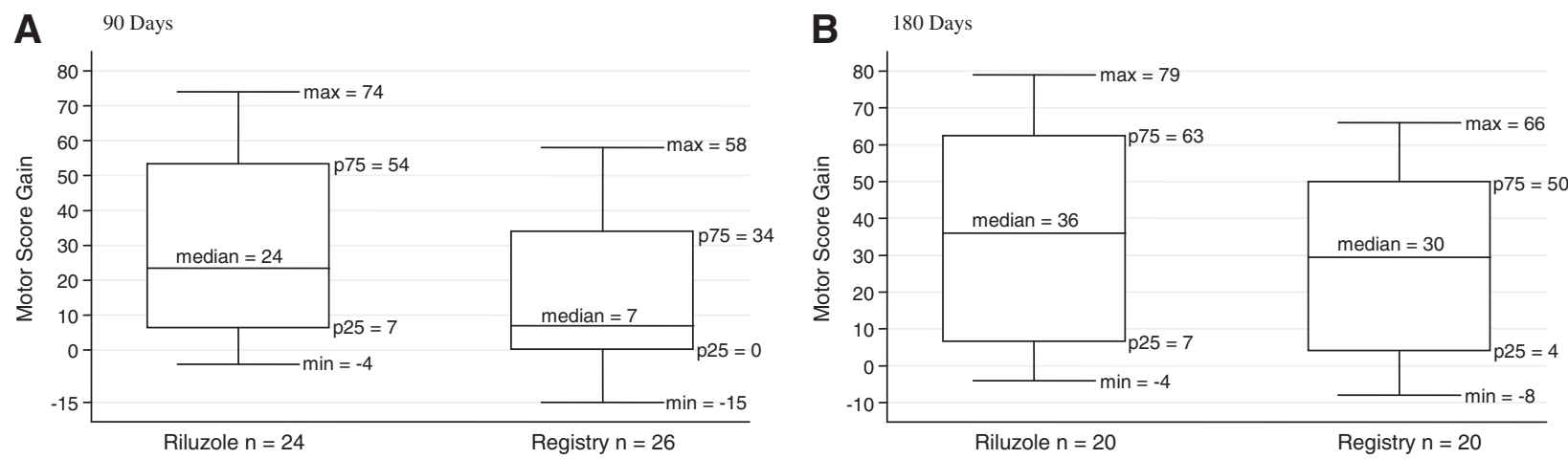

FIG. 4. Cervical injuries: riluzole and registry patients. Box plots of gains in total motor score. (A) 90 days. (B) 180 days. max, min, maximal and minimal scores encompassing at least $99 \%$ of the data; 252 , p75, 25th and 75th percentiles.

riluzole group and 7 for the registry group. At 180 days, the median value was 36 for the riluzole patients and 29.5 for the registry patients. The distribution of the data indicates more robust motor outcome in the riluzole patients.

No relationship was found between gain in motor score and time from injury to administration of riluzole.

No differences were found in outcome motor scores between the 14 patients (cervical and thoracic) who received both MPSS and riluzole and patients who received only riluzole.

\section{Cervical injuries: Progression of sensory scores}

Pin-prick scores were available at 90 days for 24 riluzole patients and for 23 registry patients, as well as at 180 days for 20 riluzole and 15 registry patients. Box plots of gain in pin-prick scores for riluzole and for registry patients at 90 and 180 days are shown in Figure 5 as an example of the changes that were observed for both light touch and for pin-prick sensation. Pin-prick scores were 10 points higher for the riluzole patients than for the registry patients at 90 days and 9 points higher at 180 days for the riluzole patients than for the registry patients, but the differences in gains were not significant. The results for light touch were similar.

\section{Cervical injuries: conversion of impairment grades at 90 days and at 180 days}

Table 13 shows the change in impairment grades from admission to 90 days for 27 patients with cervical injuries and 26 matched

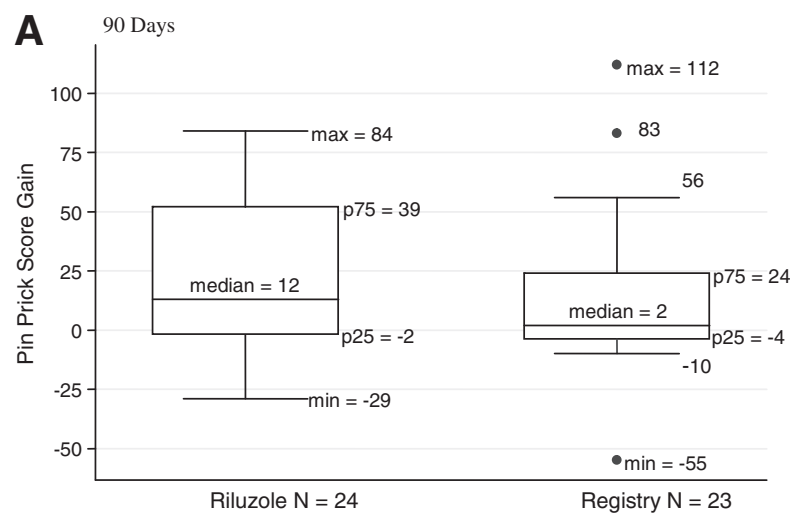

registry patients. Of 12 grade A riluzole patients, $6(50 \%)$ remained at A, $3(25 \%)$ converted to B, $2(17 \%)$ went to C, and $1(8 \%)$ to D. In contrast, of 12 grade A registry patients, $9(75 \%)$ remained at A and $1(8 \%)$ each converted to B, C, and D.

Of 8 grade $\mathrm{B}$ riluzole patients, 1 remained at $\mathrm{B}, 3$ converted to $\mathrm{C}$, and 4 converted to D. In contrast, of 8 grade B registry patients, $4(50 \%)$ remained at B, $3(38 \%)$ converted to $\mathrm{C}$, and $1(12 \%)$ converted to $\mathrm{D}$.

Of 7 grade $C$ riluzole patients, 1 remained at C (14\%), 5 (72\%) converted to D, and 1 (14\%) converted to E. In contrast, of 5 registry patients, $3(60 \%)$ remained at C and $2(40 \%)$ converted to D.

Table 14 shows conversions at 180 days for 20 patients in the riluzole cohort and 20 in the registry cohort with impairment data. The percentage of patients that converted to a more functional grade continued to be higher in the riluzole than in the registry cohort. The greatest positive effect was in grade B patients.

\section{Cervical injuries: Spinal Cord Independence Measure}

SCIM scores were available at 180 days for 20 riluzole patients and for 14 registry patients. There was no significant difference in the total score for the entire riluzole cohort, in comparison to the registry cohort. Seven B grade patients, however, had a 17.8-point mean advantage over 5 grade $\mathrm{B}$ registry patients.

\section{Thoracic injuries}

There were 8 thoracic injuries: 7 grade A and 1 grade B. At 180 days, the group exhibited a mean gain of 3 points in total motor

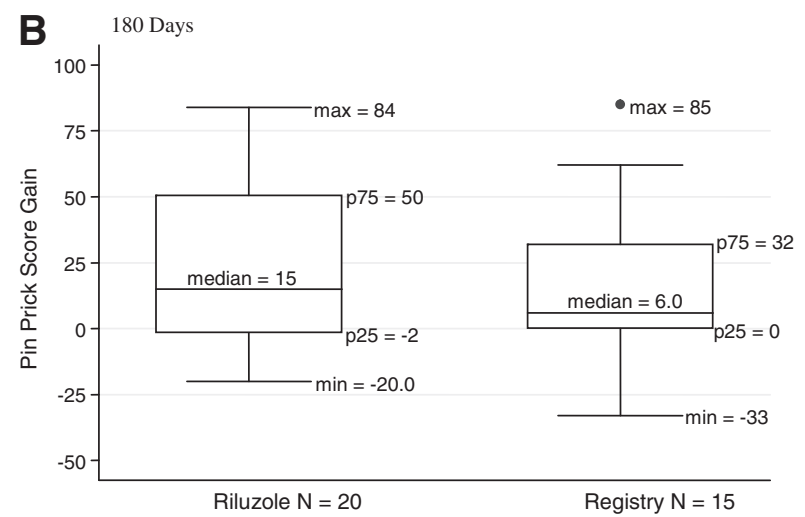

FIG. 5. Cervical injuries: riluzole and registry patients. Box plots of gains in pin-prick scores, all grades. (A) 90 days. (B) 180 days. max, min, maximal and minimal scores encompassing at least $99 \%$ of the data; 'max, 'min, outlying values; p25, p75, 25th and 75th percentiles. 
Table 13. Cervical Injuries: Riluzole AND Registry PATIENTS

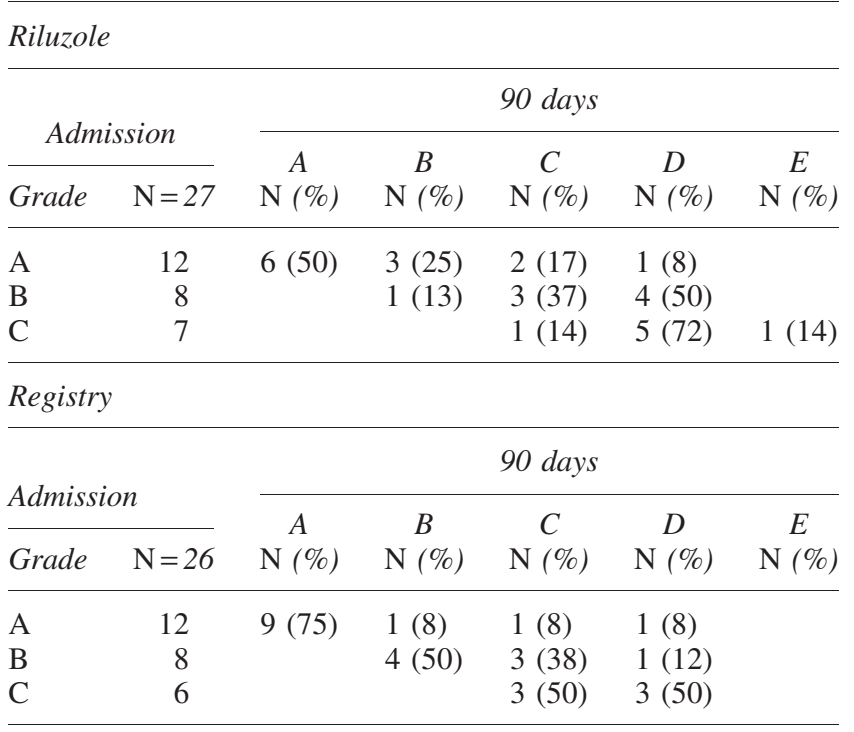

Conversions of impairment grades at 90 days.

score and a 5.2-point gain in pin-prick score. Three of the 7 grade A patients converted to a more functional grade; 2 of the 7 matched registry grade A patients converted to a more functional grade.

\section{Discussion}

\section{Feasibility of riluzole as an acutely administered} therapy for spinal cord injury

The study demonstrates that it is feasible to screen, consent, and enroll SCI patients in a clinical trial of drug therapy, obtain laboratory and radiological data, and start pharmacological therapy within $12 \mathrm{~h}$ of injury. This finding should provide encouragement for further trials of therapies that must be applied very rapidly after SCI.

Table 14. Cervical Injuries: Riluzole AND Registry Patients

\section{Riluzole}

\begin{tabular}{|c|c|c|c|c|c|c|}
\hline \multirow{2}{*}{\multicolumn{2}{|c|}{ Admission }} & \multicolumn{5}{|c|}{180 days } \\
\hline & & \multirow{2}{*}{$\begin{array}{c}A \\
\mathrm{~N}(\%)\end{array}$} & \multirow{2}{*}{$\begin{array}{c}B \\
\mathrm{~N}(\%)\end{array}$} & \multirow{2}{*}{$\begin{array}{c}C \\
\mathrm{~N}(\%)\end{array}$} & \multirow{2}{*}{$\begin{array}{c}D \\
\mathrm{~N}(\%)\end{array}$} & \multirow{2}{*}{$\begin{array}{c}E \\
\mathrm{~N}(\%)\end{array}$} \\
\hline Grades & $\mathrm{N}=20$ & & & & & \\
\hline A & 7 & $5(71)$ & 1 (14) & $0(0)$ & 1 (14) & $0(0)$ \\
\hline B & 7 & & & $2(29)$ & $5(71)$ & $0(0)$ \\
\hline $\mathrm{C}$ & 6 & & & $1(17)$ & $4(64)$ & $1(17)$ \\
\hline
\end{tabular}

Registry

\begin{tabular}{|c|c|c|c|c|c|c|}
\hline \multirow{2}{*}{\multicolumn{2}{|c|}{ Admission }} & \multicolumn{5}{|c|}{180 days } \\
\hline & & \multirow{2}{*}{$\begin{array}{c}A \\
\mathrm{~N}(\%)\end{array}$} & \multirow{2}{*}{$\begin{array}{c}B \\
\mathrm{~N}(\%)\end{array}$} & \multirow{2}{*}{$\begin{array}{c}C \\
\mathrm{~N}(\%)\end{array}$} & \multirow{2}{*}{$\begin{array}{c}D \\
\mathrm{~N}(\%)\end{array}$} & \multirow{2}{*}{$\begin{array}{c}E \\
\mathrm{~N}(\%)\end{array}$} \\
\hline Grades & $\mathrm{N}=20$ & & & & & \\
\hline A & 9 & 7 (78) & $1(11)$ & $0(0)$ & $1(11)$ & $0(0)$ \\
\hline B & 5 & & $2(40)$ & $1(20)$ & $2(40)$ & $0(0)$ \\
\hline $\mathrm{C}$ & 6 & & & $0(0)$ & $6(100)$ & $0(0)$ \\
\hline
\end{tabular}

Conversions of impairment grades at 180 days.

\section{Demographic and neurological characteristics of the riluzole cohort}

The patients enrolled in the present trial were representative of the population of SCI admitted to NACTN center hospitals in the distribution of injuries between cervical and thoracic locations and in the distribution of their impairment grades. Cervical injuries comprised $78 \%$ of the patients in the present study (Table 5), and the ratio of cervical to thoracic injuries and their impairment grades were similar in the NACTN SCI Registry. Therefore, there does not appear to be selection bias of patients for the present trial.

\section{Pharmacology of riluzole in spinal cord injury}

It would be expected that for riluzole to have a therapeutic effect, a threshold level of blood-plasma concentration must be reached and that there is a therapeutic range of concentrations.

An aim of the present study was to determine whether an association could be observed between blood-plasma levels of riluzole and motor outcome scores, with the object of determining a therapeutic blood-plasma level of riluzole. The previously published report of the pharmacology of riluzole in the patients in this phase I trial indicated that on day 3 of administration, there was a 17-fold difference in maximal concentration of riluzole between the lowest and highest values $(24-409 \mathrm{ng} / \mathrm{mL})$ in different patients. The cause of the variability in blood levels is likely to be, in part, the result of differences in absorption of riluzole from the gut ${ }^{16}$ and, in part, from variability in individual body mass index (Table 4). An attempt was made to correlate $\mathrm{C}_{\max }$ and gain in motor and sensory scores for all cervical injury patients as a group and for A, B, and C subgroups. No significant correlation was found. However, there was a positive correlation for grade $\mathrm{B}$ patients when extreme, outlying motor score and $\mathrm{C}_{\max }$ values were censored. It is possible that the low levels of plasma concentration of riluzole, in some patients, did not reach a threshold for efficacy. Considering the multiple factors that determine neurological outcome, it may be difficult to achieve a correlation. Further analysis will be undertaken in a phase II study with a larger number of patients in an attempt to validate a therapeutic effect and determine a therapeutic range of plasma concentration. If a therapeutic effect and range can be established, monitoring of plasma levels and adjustment of the enteral dose would be a rational approach to therapy.

The previous publication of the pharmacology of riluzole in SCI reported on the finding of an increase in the clearance and distribution of riluzole between the 3rd and 14th days of administration that resulted in a lower plasma concentration on day 14. This finding indicates that the changing physiology of the SCI patient can affect the metabolism of drugs and emphasizes the importance of monitoring changes in drug metabolism in SCI clinical trials for evaluating safety and efficacy data. It is also another factor that suggests the possible utility of monitoring blood levels of riluzole to adjust dosage.

\section{Safety of riluzole in spinal cord injury: Medical complications and serious adverse events}

The primary aim of the phase I trial was to determine the incidence of medical complications and SAEs in SCI patients receiving riluzole. The incidence and types of complications were similar in the riluzole patients and in the comparison registry group and in the larger NACTN SCI Registry. ${ }^{22}$ There were no SAEs attributable to riluzole and no deaths. In the NACTN SCI Registry, mortality in 126 patients with impairment grade $\mathrm{A}$ was $8.7 \%$ (11 patients). The 
leading causes of death were cardiac $(n=4)$, pulmonary $(n=4)$, and multi-organ failure $(n=2)$. If the same mortality rate occurred among the 19 grade A patients in the present trial, an average mortality of 1.65 patients would be expected.

\section{Safety: Effects on liver enzymes}

Elevations of ALT and of AST are considered to be indicators of drug-induced damage to liver cells. Elevation of GGT is a lessspecific indictor of drug-induced damage to the liver. Elevation of ALP is considered to be primarily an indicator of obstruction of the bile duct. Elevation of liver enzymes has been reported in patients with ALS undergoing treatment with riluzole. ${ }^{17}$ Elevation of liver enzymes has been reported to occur acutely in patients with $\mathrm{SCI}^{23}$ and in animal models of SCI, possibly resulting from impairment of blood flow to the liver. ${ }^{24,25}$ In the present study, riluzole administration in SCI patients was associated with a mild to moderate elevation of blood levels of ALT, AST, GGT, ALP, and bilirubin, to a varying degree for each of these markers of liver function. Elevations of ALT, AST, and GGT that reached the lower levels of a severe elevation $(>5-20 \times$ ULN) occurred on one occasion in each of 1 patient for each of these enzymes. Enzyme elevations were transient and bilirubin levels were normal on the last day of riluzole administration. Mild and moderate elevation of ALT and AST in SCI patients, as reported by Shepard and Bracken, ${ }^{23}$ was confirmed to occur within the first day of injury before administration of riluzole.

\section{Neurological outcomes: Cervical injuries, motor scores}

As a phase I trial whose primary aims were determining the PK and safety of riluzole, and without a concomitant control group, the trial was not designed or powered to detect significant changes in neurological outcome. Nevertheless, a trend was observed of a more robust outcome in riluzole-treated patients.

Comparison can be made with the results of the recently published phase II placebo-controlled, randomized trial of minocycline in acute SCI. ${ }^{26}$ Minocycline administration was associated with a 14-point gain in motor score over placebo, and motor score recovery substantially reached a plateau after 3 months. In the present phase I trial, a gain of 15.5 points was found for the riluzole group of 24 patients over the comparison registry group of 26 patients. It is difficult to precisely determine the comparability of the minocycline and the riluzole treatment groups and of the registry comparison and the placebo control group with respect to the anatomical levels of injury, distribution of impairment scores, and numbers of patients. Putting the question of comparability aside, Figure 3 of the minocycline article, showing graphs of motor gains of minocycline and placebo patients, shows, for minocycline patients, a gain from admission to 190 days of approximately 28 points, and for placebo, a gain of approximately 14 points. This gain is comparable to the gain at 180 days in the present phase I riluzole trial of 31.2 points for 24 riluzole patients and of 15.7 points for 26 registry patients.

In the minocycline trial in patients with cervical injuries, LEMS had greater gains than UEMS. In the present study, the same observation was made for grade B patients with cervical injuries who received riluzole.

Comparison of gains in UEMS can also be made with a recent report of the extent of spontaneous motor recovery after traumatic cervical sensorimotor complete SCI. ${ }^{27}$ Analysis of the Sygen trial and the European Multi-Center Study about SCI (EM-SCI) databases found a 10-11-point gain in UEMS at 1 year. The riluzole grade B patients, not as severely impaired as grade A patients, achieved a UEMS gain of 14.9 points at 180 days and a LEMS gain of 29 points.

\section{Cervical injuries: Progression of sensory scores}

In the minocycline trial, cervical motor-incomplete patients had pin-prick scores that were 14 points greater than placebo patients. ${ }^{26}$ In the riluzole patients, complete and incomplete injuries in the present study had, at 180 days, a gain of 9 points over the registry patients.

\section{Cervical injuries: conversion of impairment grades}

The most robust conversions were exhibited by grade $\mathrm{B}$ patients. At 90 days, $87 \%$ of 8 grade B riluzole patients converted to a more functional grade, compared to $50 \%$ of 8 grade B registry patients. At 180 days, all 7 (100\%) of grade B riluzole patients had progressed to a more functional grade, compared to $3(60 \%)$ of 5 registry patients.

These findings can be compared to data in the recent publication of motor recovery of cervical SCI from the National Spinal Cord Injury Statistical Center (NSCISC) database. For grade B patients, from a baseline of 7 days or less, to 1 year, $34 \%$ remained at grade B and $67 \%$ converted to $\mathrm{C}(30 \%)$ and $\mathrm{D}(37 \%){ }^{28}$

Conversions of grade A patients were not as robust, and rates for riluzole and registry patients were comparable to those reported in the EM-SCI database: For grade A patients assessed within 2 weeks of injury with a final assessment at 1 year, $32 \%$ converted to a more functional grade. ${ }^{29}$ These figures are in agreement with the NSCISC database figure of $30 \%$ conversion at 1 year $^{28}$ and correspond in the present phase I study to the conversion rate for 7 grade A riluzole patients of $29 \%$ at 180 days.

It should be noted, in making comparisons with these two studies, ${ }^{28,29}$ that their baseline measurements were made within 1 week of injury in one study and within 2 weeks in the other. In the present study, baseline assessment of impairment grade was made within $12 \mathrm{~h}$ of injury. It is well recognized that within such a group of patients, spontaneous improvement may occur rapidly, which would result in a different classification of some of the patients in the group if the assessment had been made at $72 \mathrm{~h}$. However, the registry group was also assessed within $12 \mathrm{~h}$ and should be an appropriate comparison group.

\section{Cervical injuries: The Spinal Cord Independence Measure}

At 180 days, there was no significant difference between the SCIM scores of the riluzole and registry groups, although there was a trend for better scores for grade B patients.

Improvement in functional outcome is, of course, the desired goal of therapy. Further detailed study of SCIM and other functional outcome measures in a phase II trial is warranted.

\section{Thoracic injuries}

The 8 thoracic injuries in the present study were all motor complete. On admission, 1 patient had sacral sensation. There was minimal improvement of motor and sensory score in this group of patients. A recent report of the neurological outcomes of 399 thoracic complete patients in the EM-SCI database found minimal motor and sensory improvement in this group of severely injured patients. ${ }^{30}$ Motor improvement occurred predominantly in patients with low thoracic injury. There were only two such individuals in 
the present riluzole study. Therefore, a therapeutic effect of riluzole might be detected in a larger number of low thoracic injuries and in patients who are grade B or C.

\section{Limitations of the study}

The trial was open label and the patients and examiners were aware of the treatment, factors that might result in a positive bias for riluzole treatment.

The outcomes of the patients receiving riluzole were compared with a recent historical group of patients in the NACTN SCI registry and not with a contemporaneous control group, as would occur in a phase II trial. However, the comparison registry group used to evaluate outcomes was treated at NACTN hospitals operating under the same standard-of-care protocol, and many riluzole and registry patients were evaluated by the same clinical teams, which may have reduced the variability of scoring of outcome measures.

Factors other than treatment with riluzole may have influenced neurological outcome. The very short time from injury to ED admission and supportive medical care and from injury to surgical decompression and stabilization for both the riluzole and registry patients may have had a therapeutic effect, when compared to historical studies performed at earlier times, when the incidence of decompression or stabilization surgery was not as great or carried out as urgently.

The number of patients was small, particularly when stratified by impairment scores. As commonly observed in longitudinal studies of acute SCI, the number of patients available for examination decreased as patients completed inpatient rehabilitation and returned to their homes or to a care facility far from a NACTN center: Despite strenuous efforts to obtain data from all patients unable to return to a center for examination, 3 of the 27 cervical injury patients who completed the 14-day course of riluzole treatment were unavailable for examination at 90 days, and an additional 4 were unavailable at 180 days, leaving 24 riluzole patients for analysis at 90 days and 20 at 180 days. The variability of neurological outcomes of SCI patients is great, particularly of grade $\mathrm{C}$ patients, and in a small sample, even 1 or 2 patients with extreme scores can bias the results.

\section{Conclusion}

Riluzole administered enterally within $12 \mathrm{~h}$ of SCI was well tolerated. There were no SAEs attributable to riluzole. Bearing in mind the limitations of the study, the exploratory pilot data suggest that riluzole may have a beneficial effect on motor outcome in cervical SCI that was manifest at 90 days postinjury. Improvement in lower extremity motor score appeared to be the primary effect. Further study of the PK, safety, and effects of riluzole on neurological outcome in acute traumatic SCI will be carried out in a phase II trial.

\section{Acknowledgments}

This work was supported by the Christopher Reeve Foundation, Telemedicine and Advanced Technology Research Center (TATRC), United States Army Medical Research and Materiel Command (USAMRMC); Award No. W81XWH-10-2-0042, Mission Connect (a project of the TIRR Foundation), AOSpine North America Inc, a 501(c) 3 nonprofit corporation, and by AOSpine International. The authors thank Howard Monsour, MD, for his expert review of the liver enzyme data, Cara Newton and Hyvan Dang for their data acquisition and processing, and Tanisha Bernhardt for her assistance with data management.

\section{Author Disclosure Statement}

No competing financial interests exist.

\section{References}

1. Agrawal, S., and Fehlings, M. (1996). Mechanisms of secondary injury to the spinal cord axons in vitro. J. Neurosci. 16, 545-552.

2. Stys, P.K., Sontheimer, H., Ransom, B., and Waxman, S. (1993). Noninactivating, tetrodotoxin-sensitive $\mathrm{Na}+$ conductance in rat optic nerve axons. Proc. Natl. Acad. Sci. U. S. A. 90, 6976-6980.

3. Tator, C., and Fehlings, M. (1991). Review of the secondary injury theory of acute spinal cord trauma with emphasis on vascular mechanisms. J. Neurosurg. 75, 15-26.

4. Haigney, M.C., Lakatta, E.G., Stern, M.D., and Silverman, H.S. (1994). Sodium channel blockade reduces hypoxic sodium loading and sodium-dependent calcium loading. Circulation 90, 391-399.

5. Haigney, M.C., Miyata, H., Lakatta, E.G., Stern, M.D., and Silverman, H.S. (1992). Dependence of hypoxic cellular calcium loading on $\mathrm{Na}(+)-\mathrm{Ca} 2+$ exchange. Circ. Res. 71, 547-557.

6. Li, S., Mealing, G.A., Morley, P., and Stys, P.K. (1999). Novel injury mechanism in anoxia and trauma of spinal cord white matter: glutamate release via reverse $\mathrm{Na}+$-dependent glutamate transport. J. Neurosci. 19:RC16.

7. Miller, R.G., Mitchell, J.D., Lyon, M., and Moore, D.H. (2007). Riluzole for amyotrophic lateral sclerosis (ALS)/motor neuron disease (MND). Cochran Database Syst. Rev. (1), CD001447

8. Schwartz, G., and Fehlings, M. (2002). Secondary injury mechanisms of spinal cord trauma: a novel therapeutic approach for the management of secondary pathophysiology with the sodium channel blocker riluzole. Prog. Brain Res. 137, 177-190.

9. Fehlings, M., and Schwartz, G. (2001). Evaluation of the neuroprotective effects of sodium channel blockers after spinal cord injury: improved behavioral and neuroanatomical recovery with riluzole. J. Neurosurg. 94, Suppl. 2, 245-256.

10. Tator, C.H., Hashimoto, R., Raich, A., Norvell, D., Fehlings, M.G., Harrop, J.S., Guest, J.D., Aarabi, B., and Grossman, R.G. (2012). Translational potential of preclinical trials of neuroprotection through pharmacotherapy for spinal cord injury. J. Neurosurg. Spine (Suppl.) 17, 157-229.

11. Wu, Y., Satkunendrarajah, K., Teng, Y., Chow, D.S-L, Buttigieg, J., and Fehlings, M. (2013). Delayed post-injury administration of riluzole is neuroprotective in a preclinical rodent model of cervical spinal cord injury. J. Neurotrauma 30, 441-452.

12. Wilson, J.R., and Fehlings, M.G. (2013). Riluzole for acute traumatic spinal cord injury: a promising neuroprotective treatment strategy. World Neurosurg. Jan 4. doi: 10.1016/j.wneu.2013.01.001. [Epub ahead of print]

13. Grossman, R.G., Toups, E.G., Frankowski, R.F., Burau, K.D., and Howley, S.P. (2012). North American Clinical Trials Network for the Treatment of Spinal Cord Injury: goals and progress. J. Neurosurg. Spine (Suppl.) 17, 6-10.

14. Grossman, R.G., Toups, E.G., Frankowski, RF., Burau, K.D, and Howley, S.P. (2012). North American Clinical Trials Network: building a clinical trials network for spinal cord injury, in: Essentials of Spinal Cord Injury: Basic Research to Clinical Practice, M.G. Fehlings, A.R. Vaccaro, M. Boakye, S. Rossignol, J. Ditunno, A.S. Burns (eds). Thieme: New York, pps. 348-355.

15. Fehlings, M.G., Wilson, J., Frankowski, R., Toups, E.G., Aarabi, B., Harrop, J.S., Shaffrey, C.I., Harkema, S.J., Guest, J.D., Tator, C.H., Burau, K.D., Johnson, M.M., and Grossman, R.G. (2012). Riluzole for the treatment of acute traumatic spinal cord injury: rationale for and design of the NACTN phase I clinical trial. J. Neurosurg. Spine 17, 151-156.

16. Chow, D.S.L., Teng, Y., Toups, E.G., Aarabi, B., Harrop, J.S., Shaffrey, C.I., Johnson, M.M., Boakye, M., Frankowski, R.F., Fehlings, M.G., and Grossman, R.G. (2012). Pharmacology of riluzole in acute spinal cord injury. J. Neurosurg. Spine (Suppl.) 17, 129-140.

17. Lacomblez, L., Bensimon, G., Leigh, P.N., Guillet, P., and Meininger, V. (1996). Dose-ranging study of riluzole in amyotrophic lateral sclerosis. Lancet 347, 1425-1431.

18. U.S. Food and Drug Administration (FDA). (2005). Guidance for industry estimating the maximum safe starting dose in intial clinical trials for therapeutics in adult healthy volunteers. Available at: www.fda.gov/downloads/Drugs/Guidances/UCM078932.pdf. (Last accessed June 28, 2013.) 
19. Hadley, M.N., Walters, B.C., Grabb, P.A., Oyesiku, N.M., Przybylski, G.J., Resnick, D.K., Ryken, T.C., and Mielke, D.H. (2002). Guidelines for the management of acute cervical spine and spinal cord injuries. Clin. Neurosurg. 49, 407-498.

20. Kirshblum, S.C., Waring, W., Biering-Sorenson, F., Burns, S.P., Johansen, M., Schmidt-Read, M., Donovan, W., Graves, D., Jha, A., Jones, L., Mulcahey, M.J., and Krassioukov, A. (2011). Reference for the 2011 revision of the International Standards for Neurological Classification of Spinal Cord Injury. J. Spinal Cord Med. 34, 547-554.

21. Catz, A., Itzkovich, M., Agranov, E., Ring, H., Tamir, A., (1997). SCIM-spinal independence measure: a new disability scale for patients with spinal cord leisons. Spinal Cord 35, 850-856.

22. Grossman, R.G., Frankowski, R.F., Burau, K.D., Toups, E.G., Crommett, J.W., Johnson, M.M., Fehlings, M.G., Tator, C.H., Shaffrey, C.I., Harkema, S.J., Hodes, J.E., Aarabi, B., Rosner, M.K., Guest, J.D., and Harrop, J.S. (2012). Incidence and severity of acute complications after spinal cord injury. J. Neurosurg. Spine (Suppl.) 17, 119-128.

23. Shepard, M.J., and Bracken, M.B. (1994). The effect of methylprednisilone, naloxone, and spinal cord trauma on four liver enzymes: observations from NASCIS 2. National Acute Spinal Cord Injury Study. Paraplegia 32, 236-245.

24. Vertiz-Hernandez, A., Castaneda-Hernandez, G., Martinez-Cruz, A., Cruz-Antonio, L., Grijalva, I., and Guizar-Sahagun, G. (2007). L-arginine reverses alterations in drug disposition induced by spinal cord injury by increasing hepatic blood flow. J. Neurotrauma 24 , $1855-1862$.

25. Mestre, H., Alkon, T., Salazar, S., and Ibarra, A. (2011). Spinal cord injury sequelae alter drug pharmacokinetics: an overview. Spinal Cord 49, 955-960.

26. Casha, S., Zygun, D., McGowan, M.D., Bains, I., Yong, V.W., and Hurlbert, R.J. (2012). Results of a phase II placebo-controlled ran- domized trial of minocycline in acute spinal cord injury. Brain 135 , 1224-1236.

27. Steeves, J.D., Kramer, J.K., Fawcett, J.W., Cragg, J., Lammertse, D.P., Blight, A.R., Marino, R.J., Ditunno, J.F. JR., Coleman, W.P., Geisler, F.H., Guest, J., Jones, L., Burns, S., Schubert, M., Van Hedel, H.J., Curt, A.; and EMSCI Study Group. (2011). Extent of spontaneous motor recovery after traumatic cervical sensorimotor complete spinal cord injury. Spinal Cord. 49, 257-265.

28. Marino, R.J., Burns, S., Graves, D.E., Leiby, B.E., Kirshblum, S., and Lammertse, D.P. (2011). Upper- and lower-extremity motor recovery after traumatic cervical spinal cord injury: an update from the National Spinal Cord Injury database. Arch. Phys. Med. Rehab. 92, 369-375.

29. Spiess, M.R., Muller, R.M., Rupp, R., and Schuld, C.; EM-SCI Study Group, and van Hedel, HJ. (2009). Conversion in ASIA impairment scale during the first year after traumatic spinal cord injury. J. Neurotrauma 26, 2027-2036.

30. Zariffa, J., Kramer, J.L., Fawcett, J.W., Lammertse, D.P., Blight, A.R., Guest, J., Jones, L., Burns, S., Schubert, M., Bolliger, M., Curt, A., and Steeves, J.D. (2011). Characterization of neurological recovery following traumatic sensorimotor complete thoracic spinal cord injury. Spinal Cord 49, 463-471.

Address correspondence to:

Robert G. Grossman, MD

Department of Neurosurgery

Houston Methodist Hospital

6560 Fannin, Suite 944

Houston, TX 77030

E-mail: rgrossman@houstonmethodist.org 